\title{
Caught in the Bulimic Trap: Do Eating Disorders Reflect Addictive Behavior?
}

\author{
Michelle S. Goeree, John C. Ham, and Daniela Iorio ${ }^{1}$
}

January 19, 2009

\begin{abstract}
Eating disorders are an important and growing health concern, and Bulimia Nervosa (BN) accounts for the largest fraction of eating disorders. BN is characterized by recurrent episodes of "bingeeating" followed by compensatory purging, and is especially serious given its increasingly compulsive nature. However, remarkably little is known about its addictive nature and the factors determining the incidence of $\mathrm{BN}$. We use a unique panel data set to examine whether bulimic behavior satisfies the economic definition of addiction. Further, we examine whether $\mathrm{BN}$ is a rational addiction in the sense of Becker and Murphy (1988), where both the lead and lag of bulimic behaviors should help explain current behavior after controlling for observed and unobserved heterogeneity. We find there is substantial persistence in $\mathrm{BN}$ over time due to state dependence and that this result is very robust to different model specifications and identifying assumptions. Thus BN satisfies the economic definition of addictive behavior. Our results have important implications for public policy. They suggest that: i) treatment for $\mathrm{BN}$ should receive the same insurance coverage as treatment of other addictive behaviors such as alcoholism and drug addiction; ii) preventive educational programs that facilitate the detection of $\mathrm{BN}$ at an early age should be coupled with more intense (rehabilitation) treatment for individuals exhibiting addictive behaviors. Moreover, bulimic behavior also appears to be a rational addiction, although this result is more tentative as the data (and econometric theory) do not permit similar robustness checks. Finally, we find that bulimic behavior is decreasing in income and parent's education; moreover when race plays a role, African Americans are more likely to exhibit bulimic behavior. These results stand in stark contrast to the popular conceptions of who is most likely to experience $\mathrm{BN}$, and we argue that this is a result of differences in diagnosis of BN across racial and income classes.
\end{abstract}

Keywords: Economic Models of Addiction, Bulimia Nervosa, Demographics, Health Insurance JEL Codes: I12, I18

\footnotetext{
${ }^{1}$ Michelle S. Goeree is at the University of Southern California; John C. Ham is at University of Southern California, the University of Maryland, the Institute for Research on Poverty, and IZA; Daniela Iorio is at Universitat Autonoma de Barcelona. Corresponding author is Goeree (email: goeree@usc.edu) at University of Southern California 3620 S. Vermont Ave. Los Angeles, CA 90089. We thank Lynne Casper, Seth Sanders, Duncan Thomas and seminar participants at Alicante, RAND, and the Econometrics Society Meetings (San Francisco) for very helpful comments and discussions, and Heonjae Song for excellent research assistance. We are grateful to the the National Science Foundation, the Claremont McKenna Lowe Institute for Political Economy, the USC College of Letters, Arts and Sciences, the Ministerio de Educación y Ciencia (SEJ2006-00712), Ministerio de Ciencia y Tecnología (SEJ2006-00538), Consolider-Ingenio 2010 (CSD 2006-00016), and Generalitat (Barcelona Economics - xarxa CREA and 2005SGR00836) for financial support. Any opinions, findings, and conclusions or recommendations in this paper are those of the authors and do not necessarily reflect the views of the National Science Foundation. We are responsible for any errors.
} 


\section{Introduction}

Eating disorders are an important and growing health concern in the United States. According to the National Eating Disorders Association (NEDA, 2008), approximately 9 million women in the US struggle with an eating disorder (ED). To put this in perspective, in 2005, approximately 4.5 million people had Alzheimer's disease and about 2.2 million had Schizophrenia. Bulimia Nervosa (BN) accounts for the highest number of ED incidents and disproportionately affects women. ${ }^{1}$ Over the last decade 6 to $8.4 \%$ of female adolescents reported purging to lose weight (National Youth Risk Behavior Survey, 2005), and approximately $2.2 \%$ of young women were diagnosed with BN in the unique panel data set we use, the National Heart, Lung, and Blood Institute Growth and Health Study (hereafter the NHLBI Growth and Health survey). ${ }^{2}$ Furthermore, children report suffering from BN at ever younger ages - between 1988 and 1993 the average age of onset dropped from 13-17 years old to 9-12 years old (Hoek and van Hoeken, 2003).

Bulimia is characterized by recurrent episodes of "binge-eating" followed by compensatory purging. ${ }^{3} \quad$ There are serious health consequences from these binge and purge cycles including electrolyte imbalances that can cause irregular heartbeats, heart failure and death, inflammation and possible rupture of the esophagus from frequent vomiting, tooth decay, gastric rupture, muscle weakness, anemia, and malnutrition (American Psychiatric Association, 1993). The impact on adolescents and children is even more pronounced due to irreversible effects on physical development and emotional growth. ${ }^{4}$ This disorder is especially serious given that a primary characteristic of BN is the increasingly compulsive nature of the behavior (Heyman, 1996). Individuals suffering from BN report requiring more of the behavior to produce the same effect, parallel to the behavior associated with drug or alcohol addictions (Bulik et al., 1997).

Economists have been increasingly interested in issues of addiction. In this paper we follow in this tradition and use the NHLBI Growth and Health survey data to investigate whether bulimic behavior satisfies the economic definition of addiction as presented in Becker and Murphy (1988) and further developed in Becker, Grossman and Murphy (1994). The crucial questions for isolating addictive behavior are i) is there persistence in the behavior and if so, ii) does lagged behavior matter after controlling for observed and unobserved differences across individuals (Heckman, 1981)? For instance, persistence could arise if once an individual engages in bulimic behavior, it becomes more attractive to do so in the future (state dependence). On the other hand, repeated bulimic episodes may

\footnotetext{
${ }^{1}$ Lifetime prevalence of anorexia nervosa is $0.9 \%$ in women and $0.3 \%$ in men, whereas the lifetime prevalence of BN is $1.5 \%$ in women and $0.5 \%$ in men (Hudson, et al, 2007). Furthermore, approximately $80 \%$ of BN patients are female (Gidwani, 1997).

${ }^{2}$ As we describe in detail in section (3), these data contain an assessment by a panel of medical experts on ED and BN behaviors for each respondent.

${ }^{3}$ Binge-eating is the consumption of an unusually large amount of food (by social comparison) in a two-hour period accompanied by a loss of control over the eating process. Compensatory behavior includes self-induced vomiting, misuse of laxatives, diuretics, or other medications, fasting, or excessive exercise. BN is identified with frequent weight fluctuations.

${ }^{4}$ Irreversible risks include pubertal delay or arrest and impaired acquisition of peak bone mass resulting in growth retardation and increased risk of osteoporosis (Society for Adolescent Medicine, 2003).
} 
arise from differences across individuals (individual heterogeneity) that lead to different propensities to engage in BN. For example, certain women may have strong permanent tastes for bingeing and purging, the propensity to engage repeatedly in bulimic activities could be due to these differences. In this case bulimic behavior would not reflect an addiction. In this paper, we investigate whether state dependence plays an important role in the persistence of $\mathrm{BN}$ over time. Furthermore, if there is evidence of addiction, the question naturally arises of whether the behavior constitutes rational addiction in the sense of Becker and Murphy (1988). Under rational addiction both the lead and lag of bulimic behavior should help explain current behavior, after controlling for individual differences. We investigate whether BN should be considered a form of rational addiction.

The importance of studying BN in an economic (as opposed to epidemiologic) framework is manifold. First, as noted above, BN is comparable to alcohol and drug addictions, and economists have made substantial theoretical and empirical contributions to the study of addiction. Second, economic models and econometric methodology allow us to address how (and when) state dependence can be separated from individual heterogeneity. Third, economists can contribute to the literature on the relationship between BN and observed individual characteristics. The epidemiological literature often suffers from one or more of the following problems: i) focuses only on univariate correlations, ii) uses select samples, or iii) does not attempt to distinguish between correlations and the casual factors behind BN. For example, popular culture portrays BN as affecting relatively affluent, White women who are highly educated, or come from highly educated family backgrounds. To our knowledge, no empirical evidence exists to confirm or deny this assertion. Furthermore, since race, family income and parents' education are highly correlated, even if this assertion is true, it is not clear which of these factors is most strongly associated with $\mathrm{BN}$.

The issue of whether bulimic behavior is addictive has important policy implications. If state dependence is the most important cause of persistence in $\mathrm{BN}$, then it is reasonable to instruct a wide range of young women on what constitutes addictive behavior, and urge them to get help if they persistently binge and purge. On the other hand, if individual heterogeneity is the driving force behind $\mathrm{BN}$, then programs focused more narrowly on high risk individuals will probably be most effective. Further, whether BN represents addictive behavior has important implications for financial support for treatment. Currently, BN is considered a disorder, not an addiction, and this leads to limited insurance coverage for treatment as compared to alcohol and drug addictions (NEDA, 2008). Because the latter are considered addictive diseases, patients are eligible to receive federal, state, and local funds to help with recovery, while insurance companies and employment benefits packages are required to provide payment for treatment. ${ }^{5}$

The outline of the paper is as follows. In section 2 we present a brief review of the eating disorder literature and discuss the economics' addiction literature. In section 3 we describe the data and present

\footnotetext{
${ }^{5}$ As noted by the National Eating Disorders Association (2008), families frequently have to fight to get the appropriate and necessary treatment. It is not uncommon for families to spend thousands of dollars in out of pocket expenses to pay for their daughters to receive the necessary counseling and drugs to help combat the disorder. In adolescents, $\mathrm{BN}$ treatment typically involves a combination of individual therapy, family therapy, behavior modification, nutritional rehabilitation and antidepressants (American Psychiatric Association, 2000b).
} 
basic statistics on the incidence and persistence of BN. We outline our methodology for studying the incidence of $\mathrm{BN}$ and present our static results in section 4. In section 5 we present our methodology and results for the dynamic models of BN. Our empirical findings contain several important results. First, there is substantial persistence in BN over time. Second, under exogeneity assumptions that we believe are reasonable in the current context, we find consistent evidence that bulimic behavior reflects an addiction. Indeed, while unobserved heterogeneity plays an important role in the persistence of $\mathrm{BN}$, we estimate that about one half to two thirds of the persistence is due to true state dependence. These results are consistent with those from a number of robustness checks. Third, we find that BN is consistent with the Becker and Murphy (1988) definition of rational addiction, although we are unable to perform robustness checks here due to data limitations. ${ }^{6}$ Fourth, we find that bulimic behavior is decreasing in income and parent's education; moreover, when race plays a role, African Americans are more likely to exhibit BN behavior. Our findings are robust to a number of changes in estimation method and model specification. These results stand in stark contrast to the popular conceptions about $\mathrm{BN}$, and we argue below that this contrast reflects dramatic differences in diagnosing BN across race and income classes. This in turn has the important implication that much greater outreach for treatment of $\mathrm{BN}$ be made to non-Whites and individuals from low income families. We conclude in section 6 .

\section{Literature Review}

In April of 2006, the Senate Committee of Appropriations expressed concern about the "growing incidence and health consequences of eating disorders among the population" (Department of Health and Human Services, 2006). The extent of the problem, while estimated by several long-term outcome studies as being high, remains unknown. Further, while previous studies in the US have demonstrated differences in education and socioeconomic status for the prevalence of obesity (Lauderdale, 2000; Reeder et al., 1997; Robinson et al., 2001), consistent estimation of the multivariate relationship between factors such as education, social class, and race for the prevalence of BN is relatively rare. The medical literature provides a chemical and biological foundation for the potentially addictive nature of $\mathrm{BN}$ but does not address the issue directly.

Hudson et al. (2007) examine the distribution of individual characteristics among four groups with different eating disorders from the National Comorbidity Survey Replication data. They only analyze data on individuals who were diagnosed with an ED; hence the results suffer from an obvious form of selection bias. To the best of our knowledge, Reagan and Hersch (2005) is the only study to estimate the multivariate effects of socioeconomic factors on ED behavior. They investigate the frequency of binge eating (but not purging) using data from the Detroit metropolitan area. They find that there

\footnotetext{
${ }^{6}$ As we discuss in detail below, a model of rational addiction imposes inequality constraints on the parameter estimates, where the difference in coefficients is related to an individual's discount rate. Our point estimates do not satisfy this constraint, but the confidence interval for the difference in the coefficients is very large and contains many values that do satisfy the constraint. Thus we believe this is an example of the well known problem of estimating discount rates in dynamic models.
} 
are no race and age effects on bingeing behavior, and that marital status, neighborhood, and income play a role among women. Our work differs from these two papers along many dimensions: i) we focus on BN (both binge eating and purging), ii) have additional cross-section variables such as parent's education, iii) consider nonlinear estimators appropriate for limited dependent variables, fixed effects estimators, and dynamic models, and iv) have somewhat wider geographic variation. Finally, the focus of our paper is on the potentially addictive nature of eating disorders behaviors.

The increasingly compulsive nature of eating disorders behaviors indicates that BN may represent an addiction. The ED literature indicates that there is biological support for an addictive interpretation of BN and some studies have found that genetic factors may play a role in BN incidence (Lilenfeld et al., 1998; Bulik et al., 2003). Specifically, the auto-addiction-opioid theory posits that ED is an addiction to the body's production of opioids. Starving, bingeing, purging, and exercise increase the body's $\beta$-endorphin levels, resulting in the same chemical effect as that delivered by opiates. Medical research provides further support of this hypothesis. For instance, Bencherif et al., (2005) compare women with BN to healthy women of the same age and weight. Their brains were scanned using positron emission tomography (PET) after injection with a radioactive compound that binds to opioid receptors. The opioid receptor binding in bulimic women was lower than in healthy women in the area of the brain involved in processing taste, as well as the anticipation and reward of eating. This reaction has been found in other studies of addictive behavioral disorders, including drug addiction and gambling. Finally, some studies in the biological literature suggest that there may be a genetic component to BN beyond the production of opioids. ${ }^{7}$

Furthermore, bulimics appear to persist in their behaviors. For example, 35\% of individuals who engaged in bulimic episodes in the past continue to do so (Keel et al., 2005), and only about half of the patients diagnosed with BN fully recover, many experiencing bulimic episodes for decades. The seminal papers of Stigler and Becker (1977) and Becker and Murphy (1988) (hereafter BM) showed that addiction can be consistent with forward-looking, rational utility maximizing behavior. ${ }^{8}$ Becker, Grossman and Murphy (1994) (hereafter BGM) used the framework of BM to examine whether addiction to cigarettes is rational, i.e. whether individuals consider that, due to the addictive nature of the behavior, their actions today will affect their future behavior and utility. For addiction to be rational, BM and BGM show that both leads and lags of the behavior should (positively) affect current behavior after controlling for unobserved heterogeneity. Moreover they show that the coefficient on lagged behavior should generally be larger than that on the lead behavior, and that as the ratio of the lead coefficient to the lag coefficient approaches one, the implied discount rate approaches zero. ${ }^{9}$

A number of papers have empirically tested the rational addiction model (see Chaloupka and

\footnotetext{
${ }^{7}$ See for instance, Bulik et al., 2003; Steiger, et al., 2004; and Frank, et al., 2004.

8 The Becker et al. approach has been criticized because there is no possibility for regret. Departing from rational addiction theory, Orphanides and Zervos (1995), and (1998) introduce regret either in a learning framework or in a myopic framework. Gruber and Koszegi (2001) consider that individuals may have time-inconsistent preferences when considering addictive behavior.

${ }^{9}$ BGM find evidence of rational addiction in their analysis of smoking behavior.
} 
Warner (2000) for a survey). This literature has focused mainly on addictive behaviors in tobacco use (Chaloupka, 1991; Keeler et al., 1993; Becker, Grossman, and Murphy, 1994; Jones, 1994; Douglas, 1998; Gilleski and Strumpf, 2005; Choo, 2000; Baltagi and Griffin, 2001) and alcohol consumption (Walters and Sloan, 1995; Grossman, Chaloupka, and Sirtalan, 1998; Baltagi and Griffin, 2002; Arcidiancono et al., 2007). Results from these papers suggest that addictions to alcohol and to cigarettes have rational forward looking elements. A few studies have examined addiction to hard drugs (BrettevilleJensen 1999) and to caffeine (Olekalns and Bardsley 1996). Bretteville-Jensen found that individuals who actively use heroin and amphetamines have a higher discount rate than non-users. Finally, with respect to caffeine addiction, Olekalns and Bardsley find that the BM model fits well. ${ }^{10}$ There is also a small literature examining whether addiction to food elements may be a contributing factor to the rise in obesity. Cawley (2001) is concerned with addictive elements of caloric intake; Richards et al. (2007) of food nutrients; and Rashad (2006) of caloric intake, smoking, and exercise. These papers find evidence of a forward looking addiction to calories (Cawley, 2001) and to carbohydrates (Richards et al., 2007). The large and growing literature on obesity is related to our work in the broad sense that it pertains to food consumption, but is otherwise unrelated given that women suffering from BN are characterized by average body weight (Department of Health and Human Services, 2006).

\section{Data}

As noted above, we use the NHLBI Growth and Health survey, which includes girls from schools in Richmond, California and in Cincinnati, Ohio, as well as from families enrolled in a health maintenance organization in the Washington, DC area. ${ }^{11}$ The survey was conducted annually for ten years, and began in 1988 when the girls were aged 9-10. ${ }^{12}$ It contains substantial demographic and socioeconomic information such as age, race, parental education, and initial family income. The data also contain a number of time-varying psychological or personality indices (reflecting the potential for personality disorders). These indices play an important role in our analysis, particularly in helping to control for unobserved individual heterogeneity.

A notable aspect of the data is that all individuals were asked a number of questions about their bingeing and purging behavior. For each respondent the data contain an Eating Disorders Inventory index developed by a panel of medical experts, which was designed to assess the psychological char-

\footnotetext{
10 The majority of the papers follow, as we do, the approach of Becker, Grossman, and Murphy (1994) who analyse the first order condition for prices and quantities. Some of these papers use aggregated data, while others use micro data. A few papers (Gilleskie and Strumpf, 2005; Choo, 2000; and Arcidiacono, et al., 2007) estimate dynamic structural models which account for the limited dependent variable nature of the data. Our paper also addresses the issue that many observations involve zero consumption of the substance in question.

${ }^{11}$ Unfortunately, because of confidentiality concerns, the data do not indicate in which of these three sites an individual lives. Selection of potential schools was based on census tract data that showed approximately equal fractions of African American and White children, and the least disparity in income and education between the respondents of the two ethnic groups. The majority of the cohort, selected via the Health Maintenance Organization (HMO), was randomly drawn from a membership list of potentially eligible families with nine (or ten) year-old girls. A small percentage was recruited from a Girl Scout troop located in the same geographical area as the HMO population.

12 The attrition rate after ten years was $11 \%$.
} 
acteristics relevant to Bulimia (Garner et al., 1983). Thus a major advantage of these data is that all sample participants are evaluated regarding BN behaviors and a BN eating disorder index is developed for each participant, independent of any diagnoses or treatment they have received. This stands in contrast to many data sets, where often a measure of ED or BN behavior is only available if the respondent had been diagnosed with, or was being treated for, an ED. However, if individuals from certain income or racial groups are more likely to seek treatment for an ED, results based on data from diagnosed individuals can present a very misleading picture of the incidence of EDs. Indeed we present evidence below that suggests this is a real problem, not just a potential one.

The NHLBI Growth and Health survey was constructed to have equal numbers of African Americans and Whites, and to have approximately equal representation across different income groups for African Americans and Whites (Kimm et al., 2002). Thus it is not a nationally representative sample, and is stratified by race and income. In our view neither of these are problematic. First, if model coefficients are constant across the country the fact that it is not nationally representative is not an issue; if coefficients differ, say across urban and rural locations, it is probably more informative to run separate equations on the urban and rural data, and our results from the NHLBI Growth and Health survey can be thought of as estimating the urban coefficients. Since we treat race and family income as exogenous, there is no bias from stratifying the sample on these variables. ${ }^{13}$

To the best of our knowledge the NHLBI Growth and Health survey has not been used previously in economics, so we now describe the data and variable construction in some detail. The data consist of ten waves of 2379 girls. Starting in 1990, when the girls were aged 11-12, the survey contains questions on $\mathrm{BN}$ behavior that were asked approximately every other year (in waves 3, 5, 7, 9, and 10). The BN questions were developed by a panel of medical experts who were experienced in treating BN patients and familiar with the literature on the disorder (Garner et al., 1983). The questions were formulated to be consistent with the clinical definition of BN. ${ }^{14}$ Respondents' answers were categorized and the survey reports an Eating Disorders Inventory Bulimia subscale (hereafter the ED$\mathrm{BN}$ index), which measures degrees of behavior associated with BN. The ED-BN index is constructed based on the subjects responses ("always" $=1$, "usually" $=2$, "often" $=3$, "sometimes" $=4$, "rarely" $=5$, and "never" =6) to seven items: 1) I eat when I am upset, 2) I stuff myself with food, 3) I have gone on eating binges where I felt that I could not stop, 4) I think about bingeing (overeating), 5) I eat moderately in front of others and stuff myself when they are gone, 6) I have the thought of trying to vomit in order to lose weight, and 7) I eat or drink in secrecy. A response of 4-6 on a given question contributes zero points to the ED-BN index; a response of 3 contributes 1 point; a response of 2 contributes 2 points; and a response of 1 contributes 3 points. The ED-BN index is the sum of

\footnotetext{
${ }^{13}$ Of course, if coefficients differ across the population, stratifying on exogenous variables will change the coefficients, since there is a different local approximation to the index function, but it probably does not make sense to describe the results from the stratified sample as 'biased.'

${ }^{14}$ Clinical criteria for BN, according to the Diagnostic and Statistical Manual of Mental Disorders fourth edition (DSM-IV) (American Psychiatric Assocation, 2000a), requires the cycle of binge-eating and compensatory behaviors occur at least two times a week for three months or more and that the individual feel a lack of control during the eating episodes.
} 
the contributing points and ranges from 0 to 21 in our data with a mean of 1.2. A higher score is indicative of more $\mathrm{BN}$ related problems (characterized by uncontrollable eating episodes that may be followed by the desire to purge). According to the team of medical experts that developed the index (Garner et al., 1983), a score higher than 10 indicates that the girl is very likely to have a clinical case of BN. ${ }^{15}$ The ED-BN index is widely used in epidemiological and eating disorders studies and has become the "gold standard" measure of ED behaviors (Rush, et al. 2008).

The NHLBI Growth and Health survey also contains questions used to construct four other indices based on psychological criteria. Again, these indices were developed by a panel of medical experts (Garner et al., 1983). The four additional indices measure a respondent's potential for personality disorders, and below we refer to these indices collectively as the "personality indices." The first index is a measure of each girl's dissatisfaction with her body. This index is reported every year and, given the importance body image may play in the incidence of BN behaviors, we describe its construction in detail here. It is a sum of respondents answers to nine items intended to assess satisfaction with size and shape of specific parts of the body. Specifically, the statements are: 1) I think that my stomach is too big, 2) I think that my thighs are too large, 3) I think that my stomach is just the right size, 4) I feel satisfied with the shape of my body, 5) I like the shape of my buttocks, 6) I think my hips are too big, 7) I think that my thighs are just the right size, 8) I think that my buttocks are too large, 9) I think my hips are just the right size. This index ranges from 0 to 27, and again responses are scored such that a higher score indicates more dissatisfaction. ${ }^{16}$ Hereafter we refer to it as the Body Image index.

We also use three additional indices that are based on psychological criteria, measuring tendencies toward: i) perfectionism (hereafter the Perfectionism index) ii) feelings of ineffectiveness (hereafter the Ineffectiveness index), and interpersonal distrust (hereafter the Distrust index). These indices are available in waves 3,5, 9, and 10 and thus overlap with the ED-BN index availability, with the exception that the ED-BN index is also available in wave 7. The Perfectionism index is based on subject responses to six items: 1) In my family everyone has to do things like a superstar; 2) I try very hard to do what my parents and teachers want; 3) I hate being less than best at things; 4) My parents expect me to be the best; 5) I have to do things perfectly or not to do them at all; 6) I want to do very well. The subjects are offered the same responses, and the responses are scored in the same way, as in the ED-BN index. The Distrust and Ineffectiveness indices were constructed analogously. For ease of exposition, we provide details on the questions used to form the Ineffectiveness and Distrust indices

\footnotetext{
15 Answers to individual questions are not available. The index is an aggregation of qualitative numbers. The quantitative interpretation in terms of who is perceived to be suffering from clinical BN (i.e. a score higher than 10) is motivated by results from surveys among women diagnosed with BN (by the DSM-IV criteria): the average ED-BN index among this subsample was 10.8. See Garner et al. (1983) for a description of the development and validation of the ED-BN index.

16 The scoring rule is as follows: "always" $=6$, "usually" $=5$, "often" $=4$, "sometimes" $=3$, "rarely" = 2 , and "never" $=1$ in questions $3,4,5,7$, and 9 and "always" $=1$, "usually" $=2$, "often" $=3$, "sometimes" $=4$, "rarely" $=5$, and "never" $=6$ in questions 1, 2, 6, and 8. Again a response of 4-6 on a given question contributes zero points to the body image index; a response of 3 contributes 1 point; a response of 2 contributes 2 points; and a response of 1 contributes 3 points. The body image index is the sum of the contributing points.
} 
in Appendix A. In all cases a higher score indicates a higher level of the personality characteristic.

We report variable means, standard deviations, and the standard errors for the mean values of the NHLBI Growth and Health sample in Table 1. For all demographic variables except age we have one observation per person, while for the other variables we have multiple observations per person; we adjust the standard errors of the mean to take this into account. Approximately $2.2 \%$ of the girls have a case of clinical $\mathrm{BN}$, which is close to the national average reported from other sources, ${ }^{17}$ while the mean of the ED-BN index is 1.2. The average age of the girls over the sample is approximately 14 years, and as expected given the sample design, it is approximately equally distributed across race, income, and parent's education level. ${ }^{18}$

Table 2 illustrates the univariate relationship between the demographic variables, the ED-BN index, and the incidence of BN. In the upper panel, for a given demographic group we present the mean, standard deviation, and the standard error of the mean for the ED-BN index in columns (1)-(3) respectively. Columns (4)-(6) present the same statistics for the group for the incidence of clinical BN. Again, in each case we cluster the standard errors for the means. Note first that as the girls age, both the ED-BN index and the incidence of BN fall. Interestingly, African American girls have a statistically significant higher ED-BN index and a statistically significant higher incidence of BN than White girls. ${ }^{19}$ The ED-BN index and the incidence of clinical BN both decrease as both parental education and family income increase, and again these differences are statistically significant at standard confidence levels. These results suggest that EDs are more problematic among African American girls, girls from low income families, and girls from families with lower parental education, and thus stand in contrast to popular conceptions about the incidence of EDs. One possibility is that these univariate results will disappear once we condition on the personality indices, and that some will disappear once we condition on the other demographic variables. However, the results in the next section indicate that most of these demographic differences persist in a multivariate setting with or without conditioning on the personality characteristics indices. Below we discuss why our results are at odds with popular wisdom. Finally, in the lower panel of Table 2 we present the univariate correlations between each of the personality indices with both the ED-BN index and the incidence of clinical BN. In all cases these correlations are positive and statistically significant at the $1 \%$ level.

Finally, we present summary statistics on the persistence in the ED-BN index and the incidence of clinical BN to motivate our estimation of dynamic models. To look at persistence in the ED-BN index we consider four categories of the ED-BN index: equal to 0 , in the range $1-5$, in the range $6-10$, and greater than 10. Table 3 provides the transition rates across two year intervals for these

\footnotetext{
17 See for instance, Hudson et al. (2007) and National Eating Disorders Association (2008).

18 In almost $20 \%$ of the individual-wave observations, the girls report being depressed (they were asked about their problems with depression in waves 7 and 9). Those who are depressed have statistically significant higher ED-BN indices and incidence of clinical BN. The high comoribity of depression and ED behaviors is well-documented (see Department of Health and Human Services, 2006). We do not include depression as an explanatory variable in our analysis due to problems associated with reverse causality from BN to depression, for which we do not have an adequate instrument. The issue of reverse causality from BN to depression does not seem to have been recognized in the previous literature.

19 By construction the sample contains only African Americans and Whites.
} 
categories. $^{20}$ Note first that the higher ED-BN category, the lower the probability of having an index value of 0 at time $t+2$. Second, the higher the category for the index in $t$, the more likely the ED-BN index lies between 6 and 10 in $t+2$. Finally the higher the ED index in $t$, the more likely is the girl to be in the $11+$ category at $t+2$, i.e. the more likely she is to have clinical Bulimia. If we simply look at the correlation between the index in $t$ and the index in $t+2$, we estimate it to be 0.476 , which is statistically significant (at the $1 \%$ significance level). Finally, the conditional probability of having clinical $\mathrm{BN}$ in $t+2$ given that a girl has it in $t$ is 0.37 , while the same probability for someone who does not have clinical $\mathrm{BN}$ in $t$ is 0.01 . We draw two conclusions from these results. First, there is substantial persistence in the ED-BN index and the incidence of clinical BN, motivating our use of dynamic models. Second, the first set of transition rates indicates that a value of the ED-BN index between 0 and 10 is important for predicting the incidence of clinical $\mathrm{BN}$ in $t+2$, and that simply aggregating the ED-BN index into an incidence of clinical BN would discard valuable information. Indeed our results presented below show that coefficients are of the same sign when we analyze the ED-BN index and the incidence of clinical BN, but the former are much more precisely estimated than the latter.

\section{Econometric Specification and Results: Static Models of Bulimia}

We consider results from five model specifications: i) a linear regression structure that treats a zero value of the ED-BN index as lying on the regression line, ii) a Tobit structure for the ED-BN index, iii) a potentially more flexible (than the Tobit model) Ordered Probit structure based on the intervals for the ED-BN index that we used in Table $3{ }^{21}$ iv) a linear probability model (LPM) for the incidence of clinical BN (i.e. a value for the ED-BN index greater than 10), and v) a standard Probit model for the incidence of clinical BN. We first use these models to examine the relationship between outcomes and the socioeconomic status (SES) of the respondent. We then augment these models to study the relationship between outcomes and personality indices. We then allow for the possibility that the results are biased by a person-specific, time-invariant effect. In the linear models we address this by first-differencing while in the nonlinear models we use the Chamberlain (1984)/Wooldridge (2005) (hereafter $\mathrm{C} / \mathrm{W}$ ) approach.

To begin we estimate a linear regression (projection) of the observed value of the ED-BN index on the independent variables:

$$
y_{i t}=\beta_{0}+\beta_{1} X_{i t}+a_{t}+\delta_{i}+v_{i t},
$$

where $X_{i t}$ is a vector of explanatory variables (demographics and the personality characteristics indices described above) for individual $i$ at time $t, a_{t}$ is a time dummy (which we sometimes drop), $\delta_{i}$ is an

\footnotetext{
${ }^{20}$ Recall that the ED-BN index is only available approximately every two years.

21 As noted above the Ordered Probit model is based on the categories for the ED-BN index equal to $0 ; 1-5 ; 6-10$ and greater than 10. We estimate the limit points in the Ordered Probit and thus this model is potentially more flexible than the Tobit model.
} 
individual-specific effect and $v_{i t}$ is a contemporaneous shock. To begin with we treat $\delta_{i}$ as uncorrelated with the explanatory variables, and cluster the standard errors by individual to control for correlation across time due to individual components, as well as the induced heteroskedasticity in the linear models.

For the Tobit estimates, we assume that the latent variable underlying ED-BN index takes the form

$$
y_{i t}^{*}=\varphi_{0}+\varphi_{1} X_{i t}+b_{t}+\mu_{i}+e_{i t}
$$

where the change in notation is obvious. The observed value, $y_{i t}$, of the ED-BN index is given by

$$
y_{i t}=\left\{\begin{array}{c}
0 \text { if } y_{i t}^{*} \leq 0 \\
y_{i t}^{*} \text { otherwise. }
\end{array}\right.
$$

We begin by assuming that $\mu_{i}$ is an independently and identically distributed (across individuals) $N\left(0, \sigma_{\mu}^{2}\right)$ individual-specific random effect and that $e_{i t}$ is i.i.d. $N\left(0, \sigma_{e}^{2}\right)$ (over time and individuals). We then estimate the model by forming a quasi-likelihood of the period by period observations where standard errors are clustered by individual. ${ }^{22}$ We compare the regression coefficients to the Tobit partial effects, which are very similar for the static models.

In estimating the Tobit and linear regression models, we treat the sum of the answers to the ED$\mathrm{BN}$ index questions as a quantitative variable for which the difference between the values of 2 and 3 , say, is the same as the difference between the values of 7 and 8, say. Alternatively, we could consider a model where the ED-BN index takes on 21 ordinal values determined by

$$
y_{i t}=\left\{\begin{array}{c}
0 \text { if } y_{i t}^{*} \leq 0 \\
1 \text { if } 0<y_{i t}^{*} \leq \alpha_{1} \\
k \text { if } \alpha_{k-1}<y_{i t}^{*} \leq \alpha_{k} \quad k=2, ., 20 \\
21 \text { if } \alpha_{20}<y_{i t}^{*} .
\end{array}\right.
$$

While (4) is very flexible, it also involves estimating the $20 \alpha$ parameters, in addition to the parameters in (1), which we think would be too many to identify using our data. Instead we estimated an Ordered Probit model (with estimated limit points) as an informal specification test of the Tobit model. The dependent variable takes the form: $z_{i t}=0$ if the ED-BN index equals $0, z_{i t}=1$ if the index is in $[1,5]$, $z_{i t}=2$ if the index is in $[6,10]$, and $z_{i t}=3$ if the index is greater than 10. Our statistical model is

\footnotetext{
22 We cannot allow for heteroskedasticity when clustering, since Tobit estimates are inconsistent unless errors are homoskedastic. We also estimated random effects Tobit models, which offer efficiency gains at the cost of assuming that the error structure is covariance stationary and that the correlation coefficient is the same across individuals. The results were very similar to the ones reported in the paper.
} 


$$
z_{i t}^{*}=\gamma_{0}+\gamma_{1} X_{i t}+\widetilde{b}_{t}+\widetilde{\mu}_{i}+e_{i t},
$$

where the sum $\left(\sigma_{\mu}^{2}+\sigma_{e}^{2}\right)$ is normalized to 1 , and

$$
z_{i t}=\left\{\begin{array}{c}
0 \text { if } z_{i t}^{*} \leq 0 \\
1 \text { if } 0<z_{i t}^{*} \leq \delta_{L 2} \\
2 \text { if } \delta_{L 2}<z_{i t}^{*} \leq \delta_{U 2} \\
3 \text { if } z_{i t}^{*}>\delta_{U 2} .
\end{array}\right.
$$

In this approach we estimate the parameters in (5) and the two $\delta$ cutoff terms. Note that if the Tobit model is strictly true, we could replace the Ordered Probit model in (5) by one where ${ }^{23}$

$$
z_{i t}^{*}=\varphi_{0}+\varphi_{1} X_{i t}+b_{t}+\mu_{i}+e_{i t}
$$

and

$$
z_{i t}=\left\{\begin{array}{c}
0 \text { if } z_{i t}^{*} \leq 0 \\
1 \text { if } 0<z_{i t}^{*} \leq 5.5 \\
2 \text { if } 5.5<z_{i t}^{*} \leq 10.5 \\
3 \text { if } z_{i t}^{*}>10.5 .
\end{array}\right.
$$

We again maximize the quasi-likelihood for the Ordered Probit model based on the period-by-period likelihood function and cluster the standard errors by individual. We compare the sign and significance of the Tobit estimates and the Ordered Probit estimates as an informal specification test; the coefficients are not directly comparable because the variance must be normalized to 1 for the Ordered Probit model with estimated limit points. ${ }^{24}$

Next we consider a linear probability model for the incidence of clinical BN (i.e., our dependent variable is $w_{i t}=0$ if the ED-BN index is less than or equal to 10 and $w_{i t}=1$ if the ED index is greater than 10); we again cluster the standard errors to allow for heteroskedasticity and correlation across individuals. Finally, we estimate a Probit model by maximizing the quasi-likelihood and clustering the standard errors by individuals.

We discussed in section 3 the possibility that the personality characteristics may be driven by time constant genetic factors. If this is the case, the individual effects above will be correlated with the independent variables, and the coefficients on the independent variables will not have a casual

\footnotetext{
${ }^{23}$ We assume it is appropriate to use the midpoint of the interval.

${ }^{24}$ We cannot use a Hausman test to compare the coefficients even if we account for the variance normalization because, even if Tobit structure is valid, estimates based on the quasi-likelihood are not efficient.
} 
interpretation. To allow for correlated individual effects in the regression and linear probability models, we simply first-difference. Of course, only the coefficients on the time-changing independent variables can be estimated. Also, as in any fixed effect model, to estimate these equations consistently we need to assume that the personality indices are strictly exogenous, conditional on the fixed effect. ${ }^{25}$ In other words, we require that

$$
E\left[v_{i s} X_{i l} \mid \delta_{i}\right]=0
$$

for all time periods $s$ and $l$. In particular, this rules out feedback from current values of the error term to future values of the explanatory variables. The strict exogeneity assumption may be more reasonable for the perfectionism, ineffectiveness and distrust indices than for the body image index, since a shock to ED behavior today may affect one's body image tomorrow. Thus we also estimate models where we only include these personality indices and exclude the body image index.

In the nonlinear models, we use the $\mathrm{C} / \mathrm{W}$ fixed effects estimators, where again we need to assume strict exogeneity. ${ }^{26}$ Specifically, for the Tobit model of equation (2) we assume that $\mu_{i}=\pi_{1} \bar{X}_{i}+$ $u_{i}$ where $\bar{X}_{i}$ is the vector of means of the explanatory variables across time, $u_{i} \sim$ iid $N\left(0, \sigma_{u}^{2}\right)$, and $E\left[e_{i s} X_{i l} \mid \mu_{i}\right]=0$ for all periods $s$ and $l$. For example, substituting for $\mu_{i}$ in (2) yields

$$
y_{i t}^{*}=\varphi_{0}+\varphi_{1} X_{i t}+b_{t}+\pi_{1} \bar{X}_{i}+u_{i}+e_{i t} .
$$

We again maximize the quasi-likelihood and cluster the standard errors for the nonlinear models.

In Table 4 we present the estimates from five estimators. The top panel gives results where we use only the demographic characteristics of the respondent as explanatory variables and do not include year dummies. The corresponding estimates with year dummies are in the lower panel. For the Tobit and Probit models we report partial effects, while for the Ordered Probit we present the coefficients as the partial effects are not straightforward to interpret. ${ }^{27}$ The vector $X_{i t}$ contains the respondent's age, a dummy variable equal to 1 if race is White, two dummy variables for parent's education (some college and four year college degree or more) and two dummy variables for initial family income (between $\$ 20,000$ and $\$ 40,000$ and over $\$ 40,000$; both in $1988 \$$ ). Thus the base case is an African American girl whose parent's have less than a high school education with a family income under $\$ 20,000$. As noted above standard errors are clustered by individual. The coefficients for the linear model and the partial effects for the Tobit model are very similar in terms of size and significance, so we discuss only the former. They show that the effect of being White, holding the other variables constant, is significantly negative, contrary to popular opinion. Further, the ED-BN index is significantly decreasing in age,

\footnotetext{
${ }^{25}$ See Wooldridge (2002), p. 253, equation (10.14).

${ }^{26}$ Chamberlain (1984) suggested controlling for the fixed effect by making it a linear function of all the values of the explanatory variable, while Wooldridge (2005) suggested the more parsimonious approach of making the fixed effect the means of the independent variables. We follow Wooldridge's approach since it makes our estimates more comparable to our dynamic fixed effects estimates.

${ }^{27}$ In all tables, we report partial effects for Probit and Tobit regressions. The corresponding coefficient estimates are presented in our on-line supplement to this paper; Goeree, Ham, Iorio 2008b.
} 
family income and parent's education. Being White decreases the ED-BN index by approximately 0.2 (almost a $17 \%$ reduction at the mean value of ED-BN of 1.2), while having the highest parental education is predicted to lower the index by approximately 0.3 (a $25 \%$ reduction) as compared to those with the lowest parental education. Finally, being in the highest family income category lowers the index by about 0.5 (more than a $40 \%$ reduction) as compared to having the lowest category of family income.

The results for race and income stand in contrast to popular opinion. Further, as we show below, these findings remain even after we condition on personality characteristics. An interesting question is why does this divergence between our results and popular conceptions occur? We believe the explanation is straightforward: popular opinion appears to be based on who has been diagnosed with an eating disorder, not (the potentially larger and different group) of those who exhibit BN behavior. For instance, in a companion paper using data from ADD Health (Goeree, Ham and Iorio, 2008a), we consider two groups of women: those who are diagnosed with an ED and those who are not necessarily diagnosed but engage in bingeing and purging behavior. We find that the incidence of diagnosis is more likely among high-income Whites (consistent with popular opinion), but bingeing and purging behavior is more prevalent among women with demographics consistent with the results from this study. ${ }^{28}$ The difference would appear to arise because girls who are African American and/or come from low income families are much less likely to be diagnosed with an ED conditional on having an ED. These results illustrate the importance of having objective information on behavior rather than relying solely on data on diagnoses.

The results from the Ordered Probit model are very similar to those from the Tobit in terms of the signs and significance of the coefficients, but as one would expect the Tobit coefficients are significant at higher confidence levels (since they are based on less-aggregated data). Finally, the Probit partial effects and LPM results (in the last two columns) are relatively similar (to each other), and have the same signs as the Tobit and Ordered Probit results. However fewer estimated coefficients are statistically significant in the Probit and LPM results, and those that are significant occur at lower confidence levels. The fact that we have substantially fewer significant coefficients in the Probit and LPM estimates is again expected, since they use much less information per person than the other methods. Indeed, our estimates illustrate the importance of not simply focusing on whether an individual has a clinical case of $\mathrm{BN}$ for understanding the determinants of this disease. When we include year dummies (the lower panel of Table 4), only the coefficients for age are affected, and these coefficients are now very noisily estimated. This latter result is not surprising given we do not have much variation in age at the start of the sample, so the girls in our sample tend to act like a single cohort, and it is well known that one cannot estimate vintage and time effects for a single cohort.

We next look at the effect of the personality characteristics indices on the ED-BN index, holding constant the demographic variables. It is well known in the medical literature that patients diagnosed

${ }^{28}$ In Goeree, Ham and Iorio (2008a) we use ADD Health to address different issues from those we consider in this paper. Most importantly, the ADD Health data are not a long enough panel to allow us to estimate dynamic models that are necessary to investigate the addictive nature of $\mathrm{BN}$. 
with BN are likely to suffer from other psychiatric disorders. ${ }^{29}$ The most common comorbidities include depression, anxiety, substance abuse, and personality traits such as high tendencies toward perfectionism, poor body image, feelings of ineffectiveness and interpersonal distrust issues. The source of the high comorbidities is not known, but some studies suggest that common familial or genetic factors may be responsible (Walters et al., 1992; Wade et al., 2000; Mangweth et al., 2003). Further, it is plausible that for body image concerns, the causality may be reversed - high levels of the ED-BN index, i.e. abusing food, may lead to a poor body image. This possibility does not seem to have been noted previously in the literature.

Table 5 contains the results for the linear model where personality indices are included as explanatory variables and the year dummies are dropped; again in all specifications we cluster the observations by individuals when calculating the standard errors. We begin by estimating the model in levels and column (1) presents results with the distrust, ineffectiveness and perfectionism indices used as explanatory variables. We exclude the body image index from column (1) since it may be more susceptible to reverse causality issues than the other personality indices, but include it in column (2), while in column (3) we include only the body image index. Note first that race, age and family income, but not parental education, are still statistically significant when we condition on personality indices, independent of which ones we condition on. Second, the ineffectiveness, perfectionism and body image indices, but not the distrust index, significantly affect the ED-BN index in the direction expected. Third, the effects of increases in the personality characteristics are not trivial. A five point increase in the ineffectiveness index and perfectionism index increase the ED-BN index by about 1.0 and 0.7 respectively, while a five point increase in the poor body image index increases the ED-BN index by about 0.2. Columns (4)-(6) report the first difference estimates of the equation, which allow for common unobserved familial or genetic factors that affect both the personality indices and the ED-BN index. These results are very similar to those from the level estimates, except that now distrust is statistically significant and has a negative sign, while we would have expected that if significant, it would have had the opposite sign. (The demographic variables are only measured at the start of the survey and thus drop out of the first difference model.) Columns (7)-(9) present the results with $\mathrm{C} / \mathrm{W}$ type fixed effects, where again the signs and significance of these estimates are reassuringly similar to the first difference estimates. This comparison is helpful as it suggests that parameter estimates in the nonlinear models are not biased by the more restrictive assumptions necessary to use the $\mathrm{C} / \mathrm{W}$ approach, since we cannot first difference in the nonlinear models.

Table 6 contains the partial effects for the Tobit model when we include the personality characteristics as explanatory variables. The results are virtually identical to those from the linear model except that the distrust variable now has a significant positive coefficient in the levels equation and an insignificant coefficient in the fixed effect specification, which is much more in line with our expectations for this coefficient. The Ordered Probit estimates in Table 7 are very similar in sign and significance to the Tobit estimates. The LPM and Probit partial effects for clinical BN (i.e., ED-BN

\footnotetext{
${ }^{29}$ For an overview of the medical literature see the papers discussed in Department of Health and Human Services (2006).
} 
index greater than 10) estimates are given in Tables 8 and 9, respectively; they are also similar to the Tobit model estimates in terms of the impact of personality characteristics, which are still very significant even though we are only exploiting zero-one information on the outcome variable.

\section{Persistence of Bulimia: The Role of State Dependence and Un- observed Heterogeneity}

In this section we consider dynamic models of addiction. We use the same five estimation methods as in the previous section. Our goal is to study the degree of persistence in bulimic behavior, and to decompose this persistence into that due to state dependence (i.e., BN behavior in the past has a casual effect on BN behavior this period) and that due to unobserved heterogeneity (i.e., some girls have persistent traits that make them more prone to bulimic behavior).

\subsection{Standard Models of Addiction}

We begin with the most basic model

$$
y_{i t}=\beta_{0}+\beta_{1} y_{i t-1}+\widetilde{\delta}_{i}+v_{i t},
$$

where $y_{i t-1}$ is the lag of the observed value of the ED-BN index and we have dropped the year dummies for ease of exposition. ${ }^{30}$ The least squares estimate of $\beta_{1}$ will reflect both unobserved heterogeneity and state dependence unless $\widetilde{\delta}_{i}$ drops out and $v_{i t}$ is not correlated over time. To reduce the role of heterogeneity we first include current explanatory variables $X_{i t}$ to obtain

$$
y_{i t}=\beta_{0}+\beta_{1} y_{i t-1}+\beta_{2} X_{i t}+\delta_{i}+v_{i t} .
$$

Conditioning on $X_{i t}$ should diminish the role of unobserved heterogeneity and make it less likely that $v_{i t}$ is correlated over time. However if $\delta_{i}$ is still part of the error term, then the least squares estimate of $\beta_{1}$ will continue to reflect, in part, unobserved heterogeneity. To allow for the presence of an individual-specific term $\delta_{i}$ which is uncorrelated with $X_{i t}$ and its lags, we consider two-stage least squares (2SLS) estimates of (10) where $X_{i t-1}$ are instrumental variables (IV); under these assumptions the estimate of $\beta_{1}$ will reflect only state dependence. ${ }^{31}$ However, if $\delta_{i}$ is correlated with $X_{i t}$ and its lags, then following Arellano and Bond (1991) we must first difference (10) to obtain

$$
\Delta y_{i t}=\beta_{0}+\beta_{1} \Delta y_{i t-1}+\beta_{2} \Delta X_{i t}+\Delta v_{i t},
$$

and estimate the parameters by 2SLS using $y_{i t-2}$ as instruments. This allows us to obtain a structural estimate of $\beta_{1}$ that reflects only state dependence when $\delta_{i}$ is correlated with $X_{i t}$ and its lags.

\footnotetext{
${ }^{30}$ If we add time dummies in any dynamic model the only real change is that age becomes very insignificant.

31 In theory we could use additional lags of the explanatory variables as IVs but this would reduce our sample size considerably.
} 
For the Tobit model, we again start by considering the simplest latent variable equation

$$
y_{i t}^{*}=\varphi_{0}+\varphi_{1} y_{i t-1}+\widetilde{\mu}_{i}+e_{i t},
$$

where $\widetilde{\mu}_{i}$ are (unobserved) individual-specific random effects and $e_{i t}$ is an uncorrelated (over time) error term, both of which are normally distributed. Again we want to estimate $\varphi_{1}$ as a structural parameter representing state dependence. However, the estimate of $\varphi_{1}$ will capture both heterogeneity and state dependence unless $\widetilde{\mu}_{i}$ drops out of the index function. To address this issue, we first add explanatory variables $X_{i t}$ to diminish the role of unobserved heterogeneity

$$
y_{i t}^{*}=\varphi_{0}+\varphi_{1} y_{i t-1}+\varphi_{2} X_{i t}+\mu_{i}+e_{i t} .
$$

Next we follow Wooldridge (2005) and model $\mu_{i}$ as a function of the mean values of the explanatory variables $\left(\overline{X_{i}}\right)$, the initial condition $\left(y_{i 0}\right)$, and an individual specific error term $c_{i}$. This yields

$$
y_{i t}^{*}=\varphi_{0}+\varphi_{1} y_{i t-1}+\varphi_{2} X_{i t}+\varphi_{3} \bar{X}_{i}+\varphi_{4} y_{i 0}+c_{i}+e_{i t} .
$$

where now the estimate of $\varphi_{1}$ reflects only state dependence.

We also again estimate a dynamic Ordered Probit model as an informal specification check on the dynamic Tobit model. Recall that $z_{i t}=0$ if the ED-BN index equals $0, z_{i t}=1$ if the ED-BN index is in $[1,5], z_{i t}=2$ if the ED-BN index is in $[6,10]$, and $z_{i t}=3$ if the ED-BN index is greater than 10 . Let $\widetilde{z}_{i t-1}$ be a 4 -dimensional column vector equal to: $(1,0,0,0)$ if $z_{i t-1}=0 ;(0,1,0,0)$ if $z_{i t-1}=1$; $(0,0,1,0)$ if $z_{i t-1}=2$ and $(0,0,0,1)$ if $z_{i t-1}=3$. The dynamic index function for this model is given by

$$
z_{i t}^{*}=\gamma_{0}+\gamma_{1} X_{i t}+\gamma_{2} \widetilde{z}_{i t-1}+\theta_{i}+u_{i t}
$$

We again estimate the parameters and the limit points of (13) and start by ignoring the correlation between $\widetilde{z}_{i t-1}$ and $\theta_{i}$ and obtain an estimate of $\gamma_{2}$ that reflects both heterogeneity and state dependence. Next we add the explanatory variables, and finally we use the Wooldridge (2005) procedure to obtain an estimate of $\gamma_{2}$ that only reflects state dependence. Persistence in this model is described by the 4 by 4 transition matrix with elements given by $\operatorname{Pr}\left(z_{i t}=k \mid z_{i t-1}=j\right.$ for $\left.k, j=0, . ., 3\right)$. For the LPM version of the model, we proceed in a manner analogous to the linear regression model, and for the Probit version we proceed in a manner analogous to the Ordered Probit model.

Table 10 contains our parameter estimates for the linear model. Column (1) presents estimates of the model where the only explanatory variable is the (assumed to be exogenous) lagged dependent variable (its coefficient is estimated at 0.44 ); not surprisingly it is very statistically significant and positive. In column (2) we add the demographic variables. The coefficient and standard error for the lag $\left(y_{i t-1}\right)$ hardly change, and the only demographic variables that are statistically significant are income and age. When we add the personality characteristics indices the lag coefficient drops substantially (columns (3) and (4)). The distrust index is statistically insignificant, but the other three indices are statistically significant and have the expected sign. In columns (5)-(7) we estimate 
the levels equation by 2SLS using $X_{i t-1}$ as instruments, and obtain a highly significant lag coefficient of around 0.18. The other coefficients have the expected sign, except that now the distrust index again has a negative and statistically significant coefficient. We also add two diagnostics. The first is a test statistic for weak instruments. Using least squares in the first stage equation for a censored dependent variable will induce heteroskedasticity, so we cannot apply the widely used rule-of-thumb for the first stage F-statistic of the excluded instruments (Staiger and Stock, 1997; and Stock and Yugo, 2005) as the F-statistic is not valid under heteroskedasticity. Instead we use the conjecture by Hansen, Hausman, and Newey (2006), which is the closest thing to a rule of thumb for this situation that we are aware of: the Wald statistic for the null hypothesis that the excluded instruments are zero in the first stage equation, minus the number of instruments $k$, should be greater than 32 . Second, when applicable, we present a Wald statistic to test the overidentifying restrictions that the instruments are valid; here the critical value is $\chi^{2}(l)$, where $l$ is the degree of overidentification. The results show that our instruments are not weak (tested for columns (5)-(7) and the overidentifying restrictions are not rejected (tested for columns (5) and (6); the model in column (7) is just identified). These tests are interesting, in that they indicate that conditional on using one of the personality characteristics to obtain identification, the other personality indices, are valid IV. Further, we specifically tested the validity of body image as an instrument conditional on identification, and obtained a low test statistic that is insignificant at conventional confidence levels.

The estimates in columns (5)-(7) are consistent if the individual effect is uncorrelated with the explanatory variables. To relax this zero correlation assumption, we present the Arellano and Bond (1991) approach of differencing before using 2SLS and present the results in column (8). We use $y_{i t-2}$ as an IV. We obtain a lag coefficient estimate of 0.23 , where the coefficient is still very statistically significant, while the body image index has the expected positive sign and is statistically significant. Again the weak instruments test is passed and we do not do an overidentifying restriction test since the model is just identified. The results in columns (5)-(8) provide strong evidence that BN should indeed be considered an addiction. Indeed, the results suggest that roughly half the persistence in the behavior is due to true state dependence, i.e., the ratios of the estimates on the lagged dependent variable in columns (5)-(8) to that in column (1).

The Tobit partial effect estimates are given in Table 11. The lag coefficient decreases as we condition on explanatory variables and add a fixed effect. Interestingly, the estimated partial effects of the lag of the ED-BN index without a fixed effect are considerably smaller than the lag coefficients from the linear regressions. However, when we add a fixed effect the partial effects of the lagged ED-BN index are quite similar to the IV lag coefficients (with and without differencing) from the linear models. Comparing the partial effects in columns (5) through (7) to those in (1), we estimate that about two thirds of the persistence is due to state dependence. The only other difference between the relevant Tobit partial effects and the IV regression results is that the distrust variable is now no longer statistically significant. Reassuringly, the Ordered Probit estimates in Table 12 tell a similar story to the Tobit model in terms of sign and significance. (Recall that it is not helpful to calculate partial effects for this model so the results are not comparable in terms of magnitude to the Tobit 
partial effects in Table 11.) The LPM model estimates for clinical Bulimia are in Table 13 and the Probit partial effects are in Table 14. These results suggest that the dynamic model is too rich for the zero-one data, since the IV regression coefficient on the lagged dependent variable is only significant if we difference the data and use the Arellano-Bond approach. Further, the Probit partial effects for the lagged incidence of BN are not significant once we include the fixed effects. These estimates do not imply that $\mathrm{BN}$ is not an addiction as the insignificant coefficients and partial effects on the lagged incidence of $\mathrm{BN}$ in columns (5)-(7) of Tables 13 and 14 respectively all have very large confidence intervals; in other words they are imprecisely estimated 'zero' coefficients. Of course, another way to look at this is to consider the tests for weak instruments in columns (5)-(8). The test for weak instruments in the LPM is passed in all specifications, although the test statistic in columns (5)(7) are much smaller than the respective statistics in Table 10, which perhaps explains the lack of significance of the lagged dependent variable in columns (5)-(7) of Table 13. Further, the test statistic for weak instruments for the Arellano-Bond procedure is much larger and of the magnitude of the test statistic in Table 10, and their approach produces a significant lag coefficient. ${ }^{32}$ Note also that the overidentifying restrictions for the instruments in columns (5) and (6) of Table 13 are not rejected (again the model in column (7) is just identified).

Our finding that $\mathrm{BN}$ is an addiction is consistent with much the scientific evidence discussed above. It is also consistent with the fact that treatment for individuals with $\mathrm{BN}$ is most effective if given early in the illness. The recovery rate is close to $80 \%$ if treated within the first 5 years, the rate falls to $20 \%$ if treatment is delayed until after 15 years (Reas et al., 2000). If state dependence was not important in the persistence of $\mathrm{BN}$, the recovery rate should be independent of the duration of $\mathrm{BN}$.

\subsection{Models of Rational Addiction}

Finally we estimate the rational addiction model of BG and BGM. Given that we study adolescent girls, one may ask whether it makes sense to discuss rational behavior. First, note that this criticism is a general one towards using rational addiction to describe smoking, alcohol abuse, or drug abuse, since most individuals addicted to these substances began their use before age 16 (Windle et al, 2008; Viner and Taylor, 2007). Second, economists consider optimal behavior of adolescents in other contexts such as staying in school or using contraceptives. We do not find it far-fetched that adolescent girls may take into account the fact that $\mathrm{BN}$ behavior now may make it more difficult to avoid $\mathrm{BN}$ behavior in the future.

As noted above, to estimate this model we include both the lead and the lag of the dependent variable. We consider only the linear regression model because i) the Wooldridge (2005) procedure has not been extended to include a lead of the dependent variable and ii) the LPM coefficients are very noisy, indicating that the data are not rich enough to estimate the model if we use only binary information of who has clinical BN. (The latter result is not surprising given that the data are not rich enough to estimate many specifications of the standard dynamic LPM model). Thus we consider

\footnotetext{
${ }^{32}$ It also suggests that the rule of thumb critical value for weak IV of 32 may be too small.
} 
the model

$$
y_{i t}=\rho_{0}+\rho_{1} y_{i t-1}+\rho_{2} y_{i t+1}+\rho_{3} X_{i t}+\mu_{i}+e_{i t},
$$

where we anticipate that $\rho_{1}>0$ and $\rho_{2}>0$. Further, if the implied interest rate equals zero then $\rho_{1}=\rho_{2}$; while it is positive if $\rho_{2}<\rho_{1}$, where the difference in the coefficients grows as the discount rate grows. We estimate the model by 2 SLS and use one lag and one lead of the body image index as IVs (that are excluded from the structural equation) for the case where we assume $\mu_{i}$ is uncorrelated with the body image index; we do not attempt to estimate the model without this assumption. We cannot use leads and lags of the other personality indices since these are not available in wave $7 .{ }^{33}$ We are concerned, a priori, that body image may not be a valid instrument. However, given data restrictions, this is the best IV available to use, and it was not rejected as an instrument in the linear regression or LPM models.

Column (1) of Table 15 presents the benchmark case where only the lag and lead (treated as exogenous) are included as explanatory variables. Not surprisingly, they are both highly positive and significant. Columns (2) and (3) present the results when we add all the psychological indices and only the body image index, respectively as explanatory variables respectively; but the lag and lead of the dependent variable are still treated as exogenous. The lag and lead of the dependent variable continue to be very significant, although their magnitude is somewhat lower. The corresponding 2SLS estimates (treating the lag and lead as endogenous) are in columns (4) and (5), using the lag and lead of body image as excluded instruments, and using all the psychological indices and only the body image index as explanatory variables, respectively. ${ }^{34}$ Note the magnitude of the lead and lag coefficients decreases by about half, and both coefficients are significantly positive, as predicted by theory. The lead coefficient is slightly bigger than the lag coefficient, and thus the point estimates imply a slightly negative discount rate. However the confidence interval for $\left(\rho_{1}-\rho_{2}\right)$ is $[-0.278,0.237]$ in column (4) and $[-0.239,0.214]$ in $(5)$, both of which include many positive values of the discount rate. This wide confidence interval would seem to be another example of the difficulty in precisely estimating discount rates in empirical work. Note that we are unable to conduct the robustness checks we used for the static model and simple dynamic model since we have only one set of variables as candidates for excluded instruments; moreover we do not have any overidentifying exclusions to test. For both these reasons the rational addiction results should be considered somewhat tentative.

\section{Conclusions}

We use a unique dataset and several estimation methods to examine the addictive nature of BN among adolescent girls. This dataset has the advantage that it contains panel data on individual behavior

\footnotetext{
${ }^{33}$ We do not have a sufficient number of observations to estimate Arellano-Bond because we lose more than half the observations.

${ }^{34}$ We do not do a test for weak instruments as rules of thumb in this setting have not be developed when there are multiple endogenous variables.
} 
relating to $\mathrm{BN}$, and our use of it produces a number of important results. First, and perhaps most importantly, we find that bulimic behavior satisfies the economic definition of an addiction. That is, lagged bulimic behavior matters after controlling for individual heterogeneity. Indeed we find that over half the persistence in $\mathrm{BN}$ is due to the addictive nature of the behavior (state dependence), but that unobserved heterogeneity is still important. Our results are robust to different estimation methods and identifying assumptions and are consistent with recent scientific findings. Our results also suggest that when a diagnosis is based on an underlying index that having the index, in addition to the zero-one diagnosis, can be very helpful to applied researchers for obtaining precise parameter estimates.

Our results suggest a two-pronged policy approach to addressing bulimic behaviors. Since state dependence is the most important cause of the persistence in $\mathrm{BN}$, it is important to instruct a wide range of young women on the addictive nature of $\mathrm{BN}$ and the importance of getting help, even at the initial stages of bingeing and purging behaviors. In addition, since individual heterogeneity is also important, programs focused more narrowly on high risk individuals are also likely to be effective. Further, our results strongly suggest that BN should be treated as an addiction, rather than only as a disorder, as is currently the case. This change would put those exhibiting BN on equal footing (from a treatment reimbursement perspective) with individuals abusing drugs or alcohol, and would make those with BN eligible to receive federal, state, and local funds to help with their recovery, and require insurance companies and employment benefits packages to provide payment for the treatment for BN.

Second, we find evidence that BN is consistent with rationally addictive behavior in the sense of Becker and Murphy (1988), since both the lead and lag of bulimic behaviors help explain current behavior after controlling for individual heterogeneity. However, we must make a number of caveats for this finding. First, for the linear models we can only use one estimation method and one identification strategy, unlike our work simply looking at BN as an addiction. Second, there are no appropriate econometric estimators for nonlinear models (e.g. Tobit model) of rational addiction. Third, we are concerned, a priori that body image may not be a valid instrument, and since this model is exactly identified we cannot use overidentifying restrictions to test its validity.

Finally, surprisingly little is known about the factors determining the incidence of BN, and we fill this gap in the literature. We find that $\mathrm{BN}$ behavior is decreasing in income and parent's education; moreover when race plays a role, African Americans are more likely to exhibit bulimic behavior. These results stand in stark contrast to the popular conceptions about BN. Based on evidence here and in Goeree, Ham and Iorio (2008a), we argue that this disparity occurs because affluent white teenage girls are much more likely to be diagnosed with BN conditional on having it. This in turn has the important implication that much greater outreach for treatment of $\mathrm{BN}$ be made to non-Whites and individuals from low income families. 


\section{References}

American Psychiatric Association (APA) (1993) "Practice Guideline for Eating Disorders" American Journal of Psychiatry 150: 212-228.

American Psychiatric Association (APA) (2000a) Diagnostic and Statistical Manual of Mental Disorders American Psychiatric Press: Washington DC. 4th Edition.

American Psychiatric Association (APA) (2000b) "Practice Guideline for the Treatment of Patients with Eating Disorders (Revision)" American Journal of Psychiatry 15: 1-39.

Arcidiacono P., H. Sieg, and F. Sloan (2007) "Living Rationally Under The Volcano? An Empirical Analysis Of Heavy Drinking And Smoking" International Economic Review 48: 37-65.

Arellano and Bond (1991) "Some Tests of Specification for Panel Data: Monte Carlo Evidence and an Application to Employment Equations" Review of Economic Studies 58: 277-97.

Baltagi B. and J.M. Griffin (2001) "The Econometrics of Rational Addiction: The Case of Cigarettes" Journal of Business \& Economic Statistics 19: 449-454.

Baltagi B., and J.M. Griffin (2002) "Rational Addiction to Alcohol: Panel Data Analysis of Liquor Consumption" Health Economics 11: 485-491.

Becker, G.S. and K.M. Murphy (1988) "A Theory of Rational Addiction" Journal of Political Economy 94: 675-700.

Becker, G.S., M. Grossman, and K.M. Murphy (1994) "An Empirical Analysis of Cigarettes Addiction" American Economic Review 84: 396-418.

Bencherif B., A.S. Guarda, C. Colantuoni, H. Ravert, R. Dannals, and J. Frost (2005) "Regional $\mu$-Opioid Receptor Binding in Insular Cortex is Decreased in Bulimia Nervosa and Correlates Inversely with Fasting Behavior" The Journal of Nuclear Medicine 46: 1349-1351.

Bretteville-Jensen, A.L. (1999) "Addiction and Discounting" Journal of Health Economics 18: 393-407.

Bulik, C., P. Sullivan, P. Joyce, and F. Carter (1997) "Lifetime Comorbidity of Alcohol Dependence in Women with Bulimia Nervosa" Addictive Behaviors 22: 437-446.

Bulik, C., B. Devlin, and S. Bacanu (2003) "Significant Linkage on Chromosome 10p in Families with Bulimia Nervosa" American Journal of Human Genetics 72: 200-207.

Cawley, J. (2001) "Addiction and the Consumption of Calories: Implications for Obesity" NBER Working Paper.

Chaloupka. F. (1991) "Rational Addictive Behavior and Cigarette Smoking" Journal of Political Economy 99: 722-742.

Chaloupka F. and Warner (2000) "The Economics of Smoking" in Handbook of Health Economics . North Holland.

Chamberlain G. (1984) "Panel Data" in Z. Griliches and M.D. Intriligator (eds.), Handbook of Econometrics, Volume 2. Amsterdam: North Holland, 1247-1318. 
Choo, E. (2000) "Rational Addiction and Rational Cessation: A Dynamic Structural Model of Cigarette Consumption" Working Paper.

Department of Health and Human Services (2006) Agency for Healthcare Research and Quality, Management of Eating Disorders, Evidence Report/Technology Assessment, Number 135, 2006. AHRQ publication 06-E010. Senate Report accompanying the 2006 budget as reported by the Eating Disorders Coalition. URL: www.eatingdisorderscoalition.org.

Douglas, S. (1998) "The Duration of the Smoking Habit" Economic Inquiry 36: 49-64.

Frank, G., U. Bailer, and S. Henry (2004) "Neuroimaging Studies in Eating Disorders" CNS Spectrums 9: 539-48.

Garner, D., P. Marion, M.A. Olmstead, and J. Polivy (1983) "Development and Validation of a Multidimensional Eating Disorder Inventory for Anorexia Nervosa and Bulimia" International Journal of Eating Disorders 2: 15-34.

Gidwani, G.P. and E.S. Rome (1997) Eating Disorders. Clinical Obstetrics and Gynecology, 40: 601-615.

Gilleskie, D.B. and K. S. Strumpf (2005) "The Behavioral Dynamics of Youth Smoking" Journal of Human Resources 40: 822-866.

Goeree, M., J. Ham and D. Iorio (2008a) "Tramatic Events and Eating Disorder Behaviors" mimeo, University of Southern California.

Goeree, M., J. Ham and D. Iorio (2008b) "Supplement to Caught in the Bulimic Trap: Do Eating Disorders Reflect Addictive Behavior?" URL: http://www-rcf.usc.edu/ goeree/addictive trap supplement.pdf.

Grossman, M., F. Chaloupka, and I. Sirtalan (1998) "An Empirical Analysis of Alcohol Addiction: Results from Monitoring the Future Panels" Economic Inquiry 36: 39-48.

Gruber, J. and B. Koszegi (2001) "Is Addiction 'Rational'? Theory and Evidence" Quarterly Journal of Economics 116: 1261-303.

Hansen, C., J. Hausman and W. Newey (2006) "Estimation with Many Instrumental Variables" mimeo, MIT Department of Economics.

Heckman, J. (1981) "Heterogeneity and State Dependence" In Sherwin Rosen (Eds), Studies in Labor Markets, Chicago: University of Chicago Press.

Hoek, H.W., and D. van Hoeken (2003) "Review of the Prevalence and Incidence of Eating Disorders" International Journal of Eating Disorders 31: 383-396.

Heyman, J. (1996) "Resolving the Contradictions of Addiction" Behavioral and Brain Sciences 19: $561-610$.

Hudson, J., E. Hiripi, H. Pope Jr, and R. Kesslre (2007) "The Prevalence and Correlates of Eating Disroders in the National Comorbidity Survey Replication" Biological Psychiatry 61: 348-358.

Jones A. (1994) "Health, Addicion, Social Interaction and the Decision to Quit Smoking" Journal of Health Economics 13: 93-110. 
Keel, P., D. Dorer, D. Franko, S. Jackson, S., and D. Herzog (2005) "Postremission Predictors of Relapse in Women with Eating Disorders" American Journal of Psychiatry 162: 2263-2268.

Keeler, T., T. Hu, P. Barnett, and W. Manning (1993) "Taxation Regulation, and Addiction: A Demand Function for Cigarettes Based on Time Series Evidence" Journal of Health Economics 12: $1-18$.

Kimm, S., B. Barton, E. Obarzanek, et al. (2002) "Obesity Development During Adolescence in a Biracial Cohort: The NHLBI Growth and Health Study" Pediatrics 110: e54.

Lauderdale, D. and P. Rathouz (2000) "Body Mass Index in a U.S. National Sample of Asian Americans: Effects of Nativity, Years since Immigration and Socioeconomic Status" International Journal of Obesity and Related Metabolical Diseases 24: 1188-94.

Lilenfeld, L., W. Kaye, and C. Greeno (1998) "A Controlled Family Study of Restricting Anorexia and Bulimia Nervosa: Comorbidity in Probands and Disorders in First-Degree Relatives" Archives of General Psychiatry 55: 603-10.

Mangweth, B., J. Hudson, H. Pope Jr., A. Hausmann, C. De Col, and N. Larid (2003) "Family Study of the Aggregation of Eating Disorders and Modd Disorders" Psychological Medicine 33: 1319-1323.

National Eating Disorders Association (2008) URL: www.nationaleatingdisorders.org. Accessed Dec 29, 2008.

National Heart, Lung, and Blood Institute Growth and Health Study Research Group (1992) "Obesity and cardiovascular disease risk factors in black and White girls: the NHLBI Growth and Health Study." American Journal of Public Health 82:1613-1619

National Youth Risk Behavior Survey (2005) URL: http://www.cdc.gov/HealthyYouth/yrbs/index.htm.

Olekalns N. and P. Bardsley (1996) "Rational Addiction to Caffeine: An Analysis of Coffee Consumption" Journal of Political Economy 104: 1100-1104.

Orphanides, A. and D. Zervos (1995) "Rational Addiction and Learning with Regret" Journal of Political Economy 103: 739-58.

Orphanides, A. and D. Zervos (1998) "Myopia and Addictive Behavior" Economic Journal 108: 75-91.

Rashad, I. (2006) "Structural Estimation of Caloric Intake, Exercise, Smoking, and Obesity" NBER Working Paper 11957.

Reagan, P. and J. Hersch (2005) "Influence of Race, Gender, and Socioeconomic Status on Binge Eating Frequency in a Population-Based Sample" International Journal of Eating Disorders 38: $252-256$.

Reas, D., D.Williamson, C. Martin, and N. Zucker (2000) "Duration of Illness Predicts Outcome for Bulimia Nervosa: A Long-term Follow-up Study" International Journal of Eating Disorders 27: $428-34$.

Reeder, B., Y. Chen, and S. Macdonal (1997) "Regional and Rural-Urban Differences in Obesity in Canada" Canadian Medical Association Journal 157: 1510-6. 
Richards, T., P. Patterson, and A. Tegene (2007) Obesity and Nutrient Consumption: A Rational Addiction?" Contemporary Economic Policy 25: 309-324.

Robinson, T., Chang, J., Haydel, K. (2001) "Overweight Concerns and Body Dissatisfaction among Third Grade Children: the Impacts of Ethnicity and Socioeconomic Status" Journal of Pediatrics 138: 181-7.

Rush, J., M. First, and D. Blacker (2008) Handbook of Psychiatric Measures American Psychiatric Publishing: Arlington, VA, 2nd Edition.

Society for Adolescent Medicine (2003) "Eating Disorders in Adolescents: Position Paper of the Society for Adolescent Medicine" Journal of Adolescent Health 33: 496-503.

Steiger, H., Gauvin, L., and M. Israel (2004) "Serotonin Function, Personality-Trait Variations, and Childhood Abuse in Women with Bulimia-Spectrum Eating Disorders" Journal of Clinical Psychiatry 65: 830-7.

Staiger D. and J. Stock (1997) "Instrumental Variables Regression with Weak Instruments" Econometrica 65: 557-586.

Stigler and Becker (1977) "De Gustibus non est Disputandum" American Economic Review 67: 76-90.

Stock, J. and M. Yogo (2005) "Testing for Weak Instruments" Chapter 5, in Identification and Inference for Econometric Models: Essays in Honor of Thomas Rothenberg Andrews, D.W.K. and J.H. Stock eds. Cambride University Press.

Viner R.M. and B. Taylor (2007) "Adult Outcomes of Binge Drinking in Adolescence: Findings from a UK National Birth Cohort" Journal of Epidemiology and Community Health 61: 902-907.

Wade, T., C. Bulik, M. Neale, and K. Kendler (2000) "Anorexia Nervosa and Major Depression: Shared Genetic and Environmental Risk Factors" American Journal of Psychiatry 157: 469-471.

Walters, E., Nealed, M., Eaves, L., Heath, A., Kessler, R., and K. Kendler (1992) "Bulimia Nervosa and Major Depression: a Study of Common Genetic and Envrionmental Factors" Psychological Medicine 22: 617-622.

Walters T. and F. Sloan (1995) "Why do People Drink? Tests of the Rational Addiction Model" Applied Economics 27: 727-736.

Windle M., Spear L.P., Fuligni A.J., Angold A., Brown J.D., Pine D., Smith G.T., Giedd J., and R.E. Dahl (2008) "Transitions into Underage and Problem Drinking: Developmental Processes and Mechanisms between 10 and 15 Years of Age" Pediatrics 121: S273-89.

Wooldridge, J.M. (2002) Econometric Analysis of Cross Section and Panel Data. MIT Press.

Wooldridge, J.M. (2005), "Simple Solutions to the Initial Conditions Problem in Dynamic, Nonlinear Panel Data Models with Unobserved Effects" Journal of Applied Econometrics 20: 39-54. 


\section{Tables}

Table 1: Descriptive Statistics

\begin{tabular}{lcccc}
\hline & Mean & $\begin{array}{c}\text { Standard } \\
\text { Deviation }\end{array}$ & $\begin{array}{c}\text { Clustered Standard } \\
\text { Error of Mean }\end{array}$ & $\begin{array}{c}\text { Number of } \\
\text { Waves }\end{array}$ \\
\hline ED-BN Index & 1.279 & 2.682 & 0.039 & $3,5,7,9,10$ \\
Clinical Bulimia & 0.022 & 0.145 & 0.002 & $3,5,7,9,10$ \\
Age & 14.363 & 2.991 & 0.014 & All 10 \\
White & 0.480 & 0.499 & 0.010 & 1 \\
Parents High School or Less & 0.250 & 0.433 & 0.009 & 1 \\
Parents Some College & 0.396 & 0.489 & 0.010 & 1 \\
Parents Bachelor Degree or More & 0.354 & 0.478 & 0.010 & 1 \\
Income less than $\$ 20,000$ & 0.316 & 0.465 & 0.010 & 1 \\
Income in [\$20000, \$40000] & 0.311 & 0.463 & 0.010 & 1 \\
Income more than $\$ 40,000$ & 0.373 & 0.484 & 0.010 & 1 \\
Body Image Index* & 8.039 & 7.554 & 0.131 & $3,5,7,9,10$ \\
Distrust Index** & 3.589 & 3.492 & 0.056 & $3,5,9,10$ \\
Ineffectiveness Index*** & 2.752 & 3.915 & 0.063 & $3,5,9,10$ \\
Perfectionism Index**** & 6.468 & 3.290 & 0.052 & $3,5,9,10$ \\
\hline Nos: Incme & & &
\end{tabular}

Notes: Income is in 1988\$; * ranges from 0 to 27 (maximal dissatisfaction); ** ranges from 0 to 21 (maximal distrust); *** ranges from 0 to 29 (maximal ineffectiveness); ${ }^{* * * *}$ ranges from 0 to 18 (maximal perfectionism). See Appendix for more detailed description of the variables. 
Table 2: Mean of ED-BN Index and Incidence of Clinical Bulimia by Characteristics

\begin{tabular}{|c|c|c|c|c|c|c|}
\hline \multirow[t]{2}{*}{ Variable ( $\%$ of sample) } & \multicolumn{3}{|c|}{ ED-BN Index } & \multicolumn{3}{|c|}{ Clinical Bulimia $(\mathrm{BN})$} \\
\hline & Mean & $\begin{array}{l}\text { Standard } \\
\text { Deviation }\end{array}$ & $\begin{array}{l}\text { Clustered } \\
\text { Std. Error }\end{array}$ & Mean & $\begin{array}{l}\text { Standard } \\
\text { Deviation }\end{array}$ & $\begin{array}{l}\text { Clustered } \\
\text { Std. Error }\end{array}$ \\
\hline \multicolumn{7}{|l|}{ Years: } \\
\hline $1989(21.65)$ & 1.814 & 3.287 & 0.070 & 0.038 & 0.191 & 0.004 \\
\hline $1991(19.81)$ & 1.610 & 3.021 & 0.067 & 0.033 & 0.178 & 0.004 \\
\hline $1993(18.51)$ & 1.098 & 2.342 & 0.054 & 0.014 & 0.117 & 0.003 \\
\hline 1995 (19.65) & 0.860 & 2.054 & 0.046 & 0.008 & 0.092 & 0.002 \\
\hline $1996(20.40)$ & 0.955 & 2.279 & 0.050 & 0.013 & 0.113 & 0.002 \\
\hline White (48.10) & 1.042 & 2.437 & 0.051 & 0.017 & 0.130 & 0.002 \\
\hline African American (51.90) & 1.498 & 2.873 & 0.058 & 0.026 & 0.158 & 0.003 \\
\hline Parents High School or Less (24.60) & 1.648 & 3.136 & 0.096 & 0.033 & 0.178 & 0.005 \\
\hline Parents Some College (39.73) & 1.325 & 2.682 & 0.060 & 0.020 & 0.141 & 0.003 \\
\hline Parents Bachelor Degree or More (35.68) & 0.973 & 2.278 & 0.055 & 0.015 & 0.122 & 0.002 \\
\hline \multicolumn{7}{|l|}{ Household Income (in 1988\$): } \\
\hline Income less than $\$ 20,000(29.56)$ & 1.721 & 3.146 & 0.086 & 0.033 & 0.179 & 0.004 \\
\hline Income in $[\$ 20000, \$ 40000] \quad(29.47)$ & 1.198 & 2.633 & 0.072 & 0.021 & 0.144 & 0.003 \\
\hline Income more than $\$ 40,000$ & 0.982 & 2.245 & 0.053 & 0.013 & 0.112 & 0.002 \\
\hline
\end{tabular}

Correlations of ED-BN Index and Clinical Bulimia with Personality Characteristics

Personality Characteristic Index

ED-BN Index

Clinical Bulimia (BN)

\begin{tabular}{llr} 
Body Image & 0.221 & 0.114 \\
Distrust & 0.213 & 0.107 \\
Ineffectiveness & 0.439 & 0.274 \\
Perfectionism & 0.229 & 0.145 \\
\hline
\end{tabular}

Notes: The top panel reports clustered standard errors of the mean. All correlations in the bottom panel are significant at the $1 \%$ level.

Table 3: ED-BN Index Transition Probabilities

\begin{tabular}{c|cccc} 
& \multicolumn{4}{|c}{ ED-BN Index Range at $\mathrm{t}+2$} \\
\hline ED-BN Index Range at $\mathrm{t}$ & 0 & {$[1,5]$} & {$[6,10]$} & $>10$ (Clinical BN) \\
\hline 0 & 80.16 & 17.90 & 1.50 & 0.43 \\
{$[1,5]$} & 51.92 & 39.80 & 6.47 & 1.82 \\
{$[6,10]$} & 31.38 & 42.86 & 17.80 & 7.96 \\
$>10$ (Clinical BN) & 21.93 & 37.97 & 20.32 & 19.79 \\
\hline Marginal Probability & \multicolumn{4}{|c}{} \\
of ED-BN Index at t+2 & 68.57 & 25.59 & 4.17 & 1.67 \\
\hline
\end{tabular}

Notes: Transition probabilities are significant at the $5 \%$ level. 
Table 4: The (Partial) Effects of Demographic Variables on BN

\begin{tabular}{|c|c|c|c|c|c|}
\hline & \multicolumn{3}{|c|}{ ED-BN Index } & \multicolumn{2}{|c|}{ Clinical Bulimia } \\
\hline & $\begin{array}{l}\text { Linear } \\
\text { Model }\end{array}$ & Tobit & $\begin{array}{l}\text { Ordered } \\
\text { Probit }^{1} \\
\end{array}$ & Probit & $\begin{array}{c}\text { Linear } \\
\text { Probability }\end{array}$ \\
\hline White & $\begin{array}{c}-0.243^{* * *} \\
(0.088)\end{array}$ & $\begin{array}{c}-0.220 * * * \\
(0.078)\end{array}$ & $\begin{array}{c}-0.108^{* * *} \\
(0.041)\end{array}$ & $\begin{array}{l}-0.003 \\
(0.004)\end{array}$ & $\begin{array}{l}-0.004 \\
(0.004)\end{array}$ \\
\hline Age & $\begin{array}{c}-0.132^{* * *} \\
(0.011)\end{array}$ & $\begin{array}{c}-0.104 * * * \\
(0.009)\end{array}$ & $\begin{array}{c}-0.051 * * * \\
(0.005)\end{array}$ & $\begin{array}{c}-0.004 * * * \\
(0.001)\end{array}$ & $\begin{array}{c}-0.004 * * * \\
(0.001)\end{array}$ \\
\hline Parents Some College & $\begin{array}{c}-0.198^{*} \\
(0.113)\end{array}$ & $\begin{array}{l}-0.104 \\
(0.090)\end{array}$ & $\begin{array}{l}-0.042 \\
(0.047)\end{array}$ & $\begin{array}{l}-0.006^{*} \\
(0.003)\end{array}$ & $\begin{array}{l}-0.010^{*} \\
(0.005)\end{array}$ \\
\hline $\begin{array}{l}\text { Parents Bachelor Degree } \\
\text { or More }\end{array}$ & $\begin{array}{c}-0.313^{* * *} \\
(0.116)\end{array}$ & $\begin{array}{c}-0.225^{* *} \\
(0.100)\end{array}$ & $\begin{array}{l}-0.100^{*} \\
(0.053)\end{array}$ & $\begin{array}{l}-0.005 \\
(0.004)\end{array}$ & $\begin{array}{l}-0.008 \\
(0.005)\end{array}$ \\
\hline Income in $[\$ 20000, \$ 40000]$ & $\begin{array}{c}-0.377 * * * \\
(0.112)\end{array}$ & $\begin{array}{c}-0.324 * * * \\
(0.087)\end{array}$ & $\begin{array}{c}-0.174 * * * \\
(0.048)\end{array}$ & $\begin{array}{l}-0.005 \\
(0.003)\end{array}$ & $\begin{array}{l}-0.009 * \\
(0.005)\end{array}$ \\
\hline Income more than $\$ 40,000$ & $\begin{array}{c}-0.488^{* * *} \\
(0.107)\end{array}$ & $\begin{array}{c}-0.405^{* * *} \\
(0.091)\end{array}$ & $\begin{array}{c}-0.209 * * * \\
(0.050)\end{array}$ & $\begin{array}{c}-0.013 * * * \\
(0.004)\end{array}$ & $\begin{array}{c}-0.016 * * * \\
(0.005)\end{array}$ \\
\hline \multicolumn{6}{|l|}{ Year Dummies Included } \\
\hline White & $\begin{array}{c}-0.227^{* * *} \\
(0.088)\end{array}$ & $\begin{array}{c}-0.205^{* * *} \\
(0.078)\end{array}$ & $\begin{array}{c}-0.100^{* *} \\
(0.041)\end{array}$ & $\begin{array}{l}-0.003 \\
(0.003)\end{array}$ & $\begin{array}{l}-0.004 \\
(0.004)\end{array}$ \\
\hline Age & $\begin{array}{c}0.010 \\
(0.060)\end{array}$ & $\begin{array}{c}0.040 \\
(0.057)\end{array}$ & $\begin{array}{c}0.024 \\
(0.030)\end{array}$ & $\begin{array}{l}-0.004 \\
(0.002)\end{array}$ & $\begin{array}{l}-0.005^{*} \\
(0.003)\end{array}$ \\
\hline Parents Some College & $\begin{array}{c}-0.193^{*} \\
(0.113)\end{array}$ & $\begin{array}{l}-0.101 \\
(0.090)\end{array}$ & $\begin{array}{l}-0.040 \\
(0.047)\end{array}$ & $\begin{array}{l}-0.006^{*} \\
(0.003)\end{array}$ & $\begin{array}{l}-0.009 * \\
(0.005)\end{array}$ \\
\hline $\begin{array}{l}\text { Parents Bachelor Degree } \\
\text { or More }\end{array}$ & $\begin{array}{c}-0.299 * * * \\
(0.116)\end{array}$ & $\begin{array}{c}-0.211^{* *} \\
(0.100)\end{array}$ & $\begin{array}{c}-0.093^{*} \\
(0.053)\end{array}$ & $\begin{array}{l}-0.005 \\
(0.004)\end{array}$ & $\begin{array}{l}-0.008 \\
(0.005)\end{array}$ \\
\hline Income in $[\$ 20000, \$ 40000]$ & $\begin{array}{c}-0.384 * * * \\
(0.112)\end{array}$ & $\begin{array}{c}-0.330 * * * \\
(0.086)\end{array}$ & $\begin{array}{c}-0.178^{* * *} \\
(0.048)\end{array}$ & $\begin{array}{l}-0.005 \\
0.003\end{array}$ & $\begin{array}{l}-0.009 \\
(0.005)\end{array}$ \\
\hline Income more than $\$ 40,000$ & $\begin{array}{c}-0.500 * * * \\
(0.106)\end{array}$ & $\begin{array}{c}-0.416 * * * \\
(0.090)\end{array}$ & $\begin{array}{c}-0.216^{* * *} \\
(0.050)\end{array}$ & $\begin{array}{c}-0.013^{* * *} \\
(0.004)\end{array}$ & $\begin{array}{c}-0.016 * * * \\
(0.005)\end{array}$ \\
\hline Sample Size & 9591 & 9591 & 9591 & 9591 & 9591 \\
\hline
\end{tabular}

Notes: Standard errors robust to both heteroskedasticity and intra-individual correlation are in in parenthesis in columns (1) and (5). Standard errors robust to intra-individual correlation are in parenthesis in (2),(3),(4). ${ }^{1}$ Ordered Probit are coefficient estimates not partial effects.

* indicates significant at the $10 \%$ level; ** at $5 \%$; *** at $1 \%$. 
Table 5: Linear Regression Estimates of the Effect of Demographic Variables and Personality Indices on the ED-BN Index

\begin{tabular}{|c|c|c|c|c|c|c|c|c|c|}
\hline & $(1)$ & $(2)$ & (3) & (4) & $(5)$ & $(6)$ & $(7)$ & $(8)$ & (9) \\
\hline White & $\begin{array}{c}-0.178^{* *} \\
(0.090)\end{array}$ & $\begin{array}{c}-0.238^{* * *} \\
(0.088)\end{array}$ & $\begin{array}{c}-0.406^{* * *} \\
(0.081)\end{array}$ & & & & & & \\
\hline Age & $\begin{array}{c}-0.068^{* * *} \\
(0.012)\end{array}$ & $\begin{array}{c}-0.087 * * * \\
(0.013)\end{array}$ & $\begin{array}{c}-0.163^{* * *} \\
(0.011)\end{array}$ & & & & & & \\
\hline Parents Some College & $\begin{array}{l}-0.086 \\
(0.110)\end{array}$ & $\begin{array}{l}-0.083 \\
(0.110)\end{array}$ & $\begin{array}{l}-0.153 \\
(0.108)\end{array}$ & & & & & & \\
\hline $\begin{array}{l}\text { Parents Bachelor Degree } \\
\text { or More }\end{array}$ & $\begin{array}{l}-0.162 \\
(0.119)\end{array}$ & $\begin{array}{l}-0.143 \\
(0.119)\end{array}$ & $\begin{array}{c}-0.193^{*} \\
(0.111)\end{array}$ & & & & & & \\
\hline Income in $[\$ 20000, \$ 40000]$ & $\begin{array}{l}-0.219 * \\
(0.112)\end{array}$ & $\begin{array}{c}-0.232^{* *} \\
(0.112)\end{array}$ & $\begin{array}{c}-0.375^{* * *} \\
(0.108)\end{array}$ & & & & & & \\
\hline Income more than $\$ 40,000$ & $\begin{array}{c}-0.233^{* *} \\
(0.109)\end{array}$ & $\begin{array}{c}-0.253^{* *} \\
(0.109)\end{array}$ & $\begin{array}{c}-0.466^{* * *} \\
(0.102)\end{array}$ & & & & & & \\
\hline Distrust Index & $\begin{array}{c}0.010 \\
(0.013)\end{array}$ & $\begin{array}{c}0.008 \\
(0.013)\end{array}$ & & $\begin{array}{c}-0.053^{* * *} \\
(0.016)\end{array}$ & $\begin{array}{c}-0.060 * * * \\
(0.016)\end{array}$ & & $\begin{array}{c}-0.031 * * \\
(0.013)\end{array}$ & $\begin{array}{c}-0.035^{* * *} \\
(0.013)\end{array}$ & \\
\hline Ineffectiveness Index & $\begin{array}{c}0.287 * * * \\
(0.018)\end{array}$ & $\begin{array}{c}0.260 * * * \\
(0.018)\end{array}$ & & $\begin{array}{c}0.215^{* * *} \\
(0.014)\end{array}$ & $\begin{array}{c}0.194 * * * \\
(0.015)\end{array}$ & & $\begin{array}{c}0.234 * * * \\
(0.011)\end{array}$ & $\begin{array}{c}0.214^{* * *} \\
(0.012)\end{array}$ & \\
\hline Perfectionism Index & $\begin{array}{c}0.136 * * * \\
(0.014)\end{array}$ & $\begin{array}{c}0.134 * * * \\
(0.014)\end{array}$ & & $\begin{array}{c}0.134 * * * \\
(0.016)\end{array}$ & $\begin{array}{c}0.130 * * * \\
(0.016)\end{array}$ & & $\begin{array}{c}0.135^{* * *} \\
(0.012)\end{array}$ & $\begin{array}{c}0.133^{* * *} \\
(0.012)\end{array}$ & \\
\hline Body Image Index & & $\begin{array}{c}0.040 * * * \\
(0.006)\end{array}$ & $\begin{array}{c}0.088^{* * *} \\
(0.006)\end{array}$ & & $\begin{array}{c}0.047 * * * \\
(0.009)\end{array}$ & $\begin{array}{c}0.067 * * * \\
(0.005)\end{array}$ & & $\begin{array}{c}0.045^{* * *} \\
(0.007)\end{array}$ & $\begin{array}{c}0.081 * * * \\
(0.005)\end{array}$ \\
\hline Constant & $\begin{array}{c}1.063^{* * *} \\
(0.243)\end{array}$ & $\begin{array}{c}1.179 * * * \\
(0.241)\end{array}$ & $\begin{array}{c}3.759 * * * \\
(0.219)\end{array}$ & $\begin{array}{l}-0.046 \\
(0.056)\end{array}$ & $\begin{array}{l}-0.106^{*} \\
(0.057)\end{array}$ & $\begin{array}{c}-0.290 * * * \\
(0.031)\end{array}$ & $\begin{array}{c}1.035^{* * *} \\
(0.232)\end{array}$ & $\begin{array}{c}1.224 * * * \\
(0.237)\end{array}$ & $\begin{array}{c}3.799 * * * \\
(0.167)\end{array}$ \\
\hline First Difference & No & No & No & Yes & Yes & Yes & No & No & No \\
\hline $\begin{array}{l}\text { Chamberlain/Wooldridge } \\
\text { Fixed Effects }\end{array}$ & No & No & No & No & No & No & Yes & Yes & Yes \\
\hline Sample Size & 6308 & 6291 & 9549 & 2639 & 2624 & 7756 & 6308 & 6291 & 9549 \\
\hline
\end{tabular}

Notes: Standard errors robust to both heteroskedasticity and intra-individual correlation are in parenthesis.

* indicates significant at the $10 \%$ level; $* *$ at $5 \%$; $* *$ at $1 \%$. The variation in the sample size comes primarily from the fact that all personality indices but the body image index are not available in wave 7 . 
Table 6: Tobit Estimates of the Partial Effects of Demographic Variables and Personality Indices on the ED-BN Index

\begin{tabular}{|c|c|c|c|c|c|c|}
\hline & $(1)$ & $(2)$ & (3) & $(4)$ & $(5)$ & $(6)$ \\
\hline White & $\begin{array}{c}-0.178^{* *} \\
(0.076)\end{array}$ & $\begin{array}{c}-0.248^{* * *} \\
(0.073)\end{array}$ & $\begin{array}{c}-0.374 * * * \\
(0.070)\end{array}$ & & & \\
\hline Age & $\begin{array}{c}-0.051 * * * \\
(0.010)\end{array}$ & $\begin{array}{c}-0.075^{* * *} \\
(0.010)\end{array}$ & $\begin{array}{c}-0.132^{* * *} \\
(0.009)\end{array}$ & & & \\
\hline Parents Some College & $\begin{array}{l}-0.022 \\
(0.086)\end{array}$ & $\begin{array}{l}-0.019 \\
(0.085)\end{array}$ & $\begin{array}{l}-0.073 \\
(0.084)\end{array}$ & & & \\
\hline Parents Bachelor Degree or More & $\begin{array}{l}-0.120 \\
(0.009)\end{array}$ & $\begin{array}{l}-0.105 \\
(0.098)\end{array}$ & $\begin{array}{l}-0.141 \\
(0.093)\end{array}$ & & & \\
\hline Income in $[\$ 20000, \$ 40000]$ & $\begin{array}{c}-0.224 * * * \\
(0.085)\end{array}$ & $\begin{array}{c}-0.242^{* * *} \\
(0.083)\end{array}$ & $\begin{array}{c}-0.323^{* * *} \\
(0.080)\end{array}$ & & & \\
\hline Income more than $\$ 40,000$ & $\begin{array}{c}-0.206^{* *} \\
(0.090)\end{array}$ & $\begin{array}{c}-0.235^{* * *} \\
(0.089)\end{array}$ & $\begin{array}{c}-0.385^{* * *} \\
(0.083)\end{array}$ & & & \\
\hline Distrust Index & $\begin{array}{c}0.022 * * \\
(0.009)\end{array}$ & $\begin{array}{c}0.020^{* *} \\
(0.009)\end{array}$ & & $\begin{array}{l}-0.007 \\
(0.010)\end{array}$ & $\begin{array}{l}-0.011 \\
(0.011)\end{array}$ & \\
\hline Ineffectiveness Index & $\begin{array}{c}0.181 * * * \\
(0.010)\end{array}$ & $\begin{array}{c}0.150^{* * *} \\
(0.009)\end{array}$ & & $\begin{array}{c}0.140 * * * \\
(0.010)\end{array}$ & $\begin{array}{c}0.117^{* * *} \\
(0.010)\end{array}$ & \\
\hline Perfectionism Index & $\begin{array}{c}0.096^{* * *} \\
(0.010)\end{array}$ & $\begin{array}{c}0.093^{* * *} \\
(0.009)\end{array}$ & & $\begin{array}{c}0.098^{* * *} \\
(0.011)\end{array}$ & $\begin{array}{c}0.096^{* * *} \\
(0.011)\end{array}$ & \\
\hline Body Image Index & & $\begin{array}{c}0.044 * * * \\
(0.004)\end{array}$ & $\begin{array}{c}0.078^{* * *} * \\
(0.004)\end{array}$ & & $\begin{array}{c}0.045^{* * *} \\
(0.006)\end{array}$ & $\begin{array}{c}0.077 * * * \\
(0.005)\end{array}$ \\
\hline $\begin{array}{l}\text { Chamberlain/Wooldridge } \\
\text { Fixed Effects }\end{array}$ & No & No & No & Yes & Yes & Yes \\
\hline Sample Size & 6308 & 6291 & 9549 & 6308 & 6291 & 9549 \\
\hline
\end{tabular}

Notes: Standard errors robust to intra-individual correlation are in parenthesis. $*$ indicates

significant at the $10 \%$ level; ** at $5 \%$; *** at $1 \%$. 
Table 7: Ordered Probit Coefficient Estimates for ED-BN Index

\begin{tabular}{|c|c|c|c|c|c|c|}
\hline & (1) & $(2)$ & (3) & (4) & (5) & (6) \\
\hline White & $\begin{array}{c}-0.098^{* *} \\
(0.044)\end{array}$ & $\begin{array}{c}-0.143 * * * \\
(0.044)\end{array}$ & $\begin{array}{c}-0.204 * * * \\
(0.040)\end{array}$ & & & \\
\hline Age & $\begin{array}{c}-0.026^{* * *} \\
(0.006)\end{array}$ & $\begin{array}{c}-0.042^{* * *} \\
(0.006)\end{array}$ & $\begin{array}{c}-0.072 * * * \\
(0.005)\end{array}$ & & & \\
\hline Parents Some College & $\begin{array}{l}-0.006 \\
(0.050)\end{array}$ & $\begin{array}{l}-0.003 \\
(0.050)\end{array}$ & $\begin{array}{l}-0.029 \\
(0.048)\end{array}$ & & & \\
\hline Parents Bachelor Degree or More & $\begin{array}{l}-0.051 \\
(0.058)\end{array}$ & $\begin{array}{l}-0.039 \\
(0.059)\end{array}$ & $\begin{array}{l}-0.061 \\
(0.054)\end{array}$ & & & \\
\hline Income in $[\$ 20000, \$ 40000]$ & $\begin{array}{c}-0.133^{* *} \\
(0.052)\end{array}$ & $\begin{array}{c}-0.149 * * * \\
(0.052)\end{array}$ & $\begin{array}{c}-0.189 * * * \\
(0.049)\end{array}$ & & & \\
\hline Income more than $\$ 40000$ & $\begin{array}{c}-0.115^{* *} \\
(0.054)\end{array}$ & $\begin{array}{c}-0.135^{* *} \\
(0.055)\end{array}$ & $\begin{array}{c}-0.215^{* * *} \\
(0.050)\end{array}$ & & & \\
\hline Distrust Index & $\begin{array}{c}0.013^{* *} \\
(0.005)\end{array}$ & $\begin{array}{c}0.012^{* *} \\
(0.005)\end{array}$ & & $\begin{array}{l}-0.001 \\
(0.008)\end{array}$ & $\begin{array}{l}-0.005 \\
(0.008)\end{array}$ & \\
\hline Ineffectiveness Index & $\begin{array}{c}0.103^{* * *} \\
(0.005)\end{array}$ & $\begin{array}{c}0.085^{* * *} \\
(0.005)\end{array}$ & & $\begin{array}{c}0.091 * * * \\
(0.007)\end{array}$ & $\begin{array}{c}0.077 * * * \\
(0.007)\end{array}$ & \\
\hline Perfectionism Index & $\begin{array}{c}0.053^{* * *} \\
(0.005)\end{array}$ & $\begin{array}{c}0.053^{* * *} \\
(0.006)\end{array}$ & & $\begin{array}{c}0.066 * * * \\
(0.008)\end{array}$ & $\begin{array}{c}0.067^{* * *} \\
(0.008)\end{array}$ & \\
\hline Body Image Index & & $\begin{array}{c}0.026 * * * \\
(0.003)\end{array}$ & $\begin{array}{c}0.044 * * * \\
(0.002)\end{array}$ & & $\begin{array}{c}0.032^{* * *} \\
(0.004)\end{array}$ & $\begin{array}{c}0.049 * * * \\
(0.003)\end{array}$ \\
\hline Constant & & & & $\begin{array}{c}0.600^{* * *} \\
(0.139)\end{array}$ & $\begin{array}{c}0.477 * * * \\
(0.143)\end{array}$ & $\begin{array}{c}-0.794 * * * \\
(0.103)\end{array}$ \\
\hline Chamberlain/Wooldridge Fixed Effects & No & No & No & Yes & Yes & Yes \\
\hline$\underline{\text { Sample Size }}$ & 6291 & 6291 & 9549 & 6291 & 6291 & 9549 \\
\hline
\end{tabular}

See notes to Table 6 . 
Table 8: Linear Probability Model Estimates for Clinical Bulimia

\begin{tabular}{|c|c|c|c|c|c|c|c|c|c|}
\hline & $(1)$ & $(2)$ & (3) & (4) & (5) & (6) & $(7)$ & $(8)$ & (9) \\
\hline White & $\begin{array}{l}-0.004 \\
(0.005)\end{array}$ & $\begin{array}{l}-0.005 \\
(0.005)\end{array}$ & $\begin{array}{c}-0.008^{* *} \\
(0.004)\end{array}$ & & & & & & \\
\hline Age & $\begin{array}{c}-0.002^{* * *} \\
(0.001)\end{array}$ & $\begin{array}{c}-0.003^{* * *} \\
(0.001)\end{array}$ & $\begin{array}{c}-0.005^{* * *} \\
(0.001)\end{array}$ & & & & & & \\
\hline Parents Some College & $\begin{array}{l}-0.005 \\
(0.006)\end{array}$ & $\begin{array}{l}-0.005 \\
(0.006)\end{array}$ & $\begin{array}{l}-0.008 \\
(0.005)\end{array}$ & & & & & & \\
\hline $\begin{array}{l}\text { Parents Bachelor Degree } \\
\text { or More }\end{array}$ & $\begin{array}{l}-0.001 \\
(0.007)\end{array}$ & $\begin{array}{l}-0.000 \\
(0.007)\end{array}$ & $\begin{array}{l}-0.004 \\
(0.005)\end{array}$ & & & & & & \\
\hline Income in $[\$ 20000, \$ 40000]$ & $\begin{array}{l}-0.001 \\
(0.006)\end{array}$ & $\begin{array}{l}-0.001 \\
(0.006)\end{array}$ & $\begin{array}{l}-0.009 * \\
(0.005)\end{array}$ & & & & & & \\
\hline Income more than $\$ 40,000$ & $\begin{array}{l}-0.008 \\
(0.006)\end{array}$ & $\begin{array}{l}-0.008 \\
(0.006)\end{array}$ & $\begin{array}{c}-0.015^{* * *} \\
(0.005)\end{array}$ & & & & & & \\
\hline Distrust Index & $\begin{array}{l}-0.001 \\
(0.001)\end{array}$ & $\begin{array}{l}-0.001 \\
(0.001)\end{array}$ & & $\begin{array}{l}-0.002 \\
(0.001)\end{array}$ & $\begin{array}{l}-0.002 * \\
(0.001)\end{array}$ & & $\begin{array}{c}-0.002^{* *} \\
(0.001)\end{array}$ & $\begin{array}{c}-0.002^{* *} \\
(0.001)\end{array}$ & \\
\hline Ineffectiveness Index & $\begin{array}{c}0.010^{* * *} \\
(0.001)\end{array}$ & $\begin{array}{c}0.010^{* * *} \\
(0.001)\end{array}$ & & $\begin{array}{c}0.010 * * * \\
(0.002)\end{array}$ & $\begin{array}{c}0.009 * * * \\
(0.002)\end{array}$ & & $\begin{array}{c}0.009 * * * \\
(0.001)\end{array}$ & $\begin{array}{c}0.008^{* * *} \\
(0.001)\end{array}$ & \\
\hline Perfectionism Index & $\begin{array}{c}0.005^{* * *} \\
(0.001)\end{array}$ & $\begin{array}{c}0.005^{* * *} \\
(0.001)\end{array}$ & & $\begin{array}{l}0.005^{* * *} \\
(0.002)\end{array}$ & $\begin{array}{c}0.005^{* * *} \\
(0.002)\end{array}$ & & $\begin{array}{c}0.004 * * * \\
(0.001)\end{array}$ & $\begin{array}{c}0.004 * * * \\
(0.001)\end{array}$ & \\
\hline Body Image Index & & $\begin{array}{l}0.001 * * \\
(0.000)\end{array}$ & $\begin{array}{c}0.002^{* * *} \\
(0.000)\end{array}$ & & $\begin{array}{l}0.002^{*} \\
(0.001)\end{array}$ & $\begin{array}{c}0.002^{* * *} \\
(0.000)\end{array}$ & & $\begin{array}{c}0.001 * * * \\
(0.000)\end{array}$ & $\begin{array}{c}0.002^{* * *} \\
(0.000)\end{array}$ \\
\hline Constant & $\begin{array}{c}0.008 \\
(0.014)\end{array}$ & $\begin{array}{c}0.011 \\
(0.014)\end{array}$ & $\begin{array}{c}0.099 * * * \\
(0.013)\end{array}$ & $\begin{array}{l}-0.000 \\
(0.004)\end{array}$ & $\begin{array}{l}-0.002 \\
(0.004)\end{array}$ & $\begin{array}{c}-0.008^{* * *} \\
(0.001)\end{array}$ & $\begin{array}{c}0.000 \\
(0.014)\end{array}$ & $\begin{array}{c}0.006 \\
(0.014)\end{array}$ & $\begin{array}{c}0.099 * * * \\
(0.010)\end{array}$ \\
\hline First Difference & No & No & No & Yes & Yes & Yes & No & No & No \\
\hline $\begin{array}{l}\text { Chamberlain/Wooldridge } \\
\text { Fixed Effects }\end{array}$ & No & No & No & No & No & No & Yes & Yes & Yes \\
\hline Sample size & 6308 & 6291 & 9549 & 2639 & 2624 & 7756 & 6308 & 6291 & 9549 \\
\hline
\end{tabular}

See notes to Table 5 . 
Table 9: Probit Estimates of the Partial Effects of Demographic Variables and Personality Indices on Clinical Bulimia

\begin{tabular}{|c|c|c|c|c|c|c|}
\hline & (1) & (2) & (3) & (4) & (5) & (6) \\
\hline White & $\begin{array}{l}-0.0054^{*} \\
(0.0030)\end{array}$ & $\begin{array}{c}-0.0065^{* *} \\
(0.0027)\end{array}$ & $\begin{array}{c}-0.0069^{* * *} \\
(0.0027)\end{array}$ & & & \\
\hline Age & $\begin{array}{c}-0.0016^{* * *} \\
(0.0005)\end{array}$ & $\begin{array}{c}-0.0019 * * * \\
(0.0004)\end{array}$ & $\begin{array}{c}-0.0035^{* * *} \\
(0.0004)\end{array}$ & & & \\
\hline Parents Some College & $\begin{array}{l}-0.0030 \\
(0.0028)\end{array}$ & $\begin{array}{l}-0.0029 \\
(0.0026)\end{array}$ & $\begin{array}{l}-0.0041 \\
(0.0026)\end{array}$ & & & \\
\hline $\begin{array}{l}\text { Parents Bachelor Degree } \\
\text { or More }\end{array}$ & $\begin{array}{l}-0.0010 \\
(0.0035)\end{array}$ & $\begin{array}{l}-0.0009 \\
(0.0033)\end{array}$ & $\begin{array}{l}-0.0019 \\
(0.0032)\end{array}$ & & & \\
\hline Income in $[\$ 20000, \$ 40000]$ & $\begin{array}{l}-0.0001 \\
(0.0031)\end{array}$ & $\begin{array}{l}-0.0004 \\
(0.0029)\end{array}$ & $\begin{array}{l}-0.0045^{*} \\
(0.0026)\end{array}$ & & & \\
\hline Income more than $\$ 40,000$ & $\begin{array}{l}-0.0046 \\
(0.0032)\end{array}$ & $\begin{array}{l}-0.0047 \\
(0.0030)\end{array}$ & $\begin{array}{c}-0.0100 * * * \\
(0.0028)\end{array}$ & & & \\
\hline Distrust Index & $\begin{array}{l}-0.0000 \\
(0.0003)\end{array}$ & $\begin{array}{l}-0.0000 \\
(0.0003)\end{array}$ & & $\begin{array}{l}-0.0003 \\
(0.0002)\end{array}$ & $\begin{array}{l}-0.0003 \\
(0.0002)\end{array}$ & \\
\hline Ineffectiveness Index & $\begin{array}{c}0.0028^{* * *} \\
(0.0003)\end{array}$ & $\begin{array}{c}0.0023^{* * *} \\
(0.0003)\end{array}$ & & $\begin{array}{c}0.0004 * * * \\
(0.0002)\end{array}$ & $\begin{array}{c}0.0008^{* * *} \\
(0.0002)\end{array}$ & \\
\hline Perfectionism Index & $\begin{array}{l}0.002^{* * *} \\
(0.0003)\end{array}$ & $\begin{array}{c}0.0018^{* * *} \\
(0.0003)\end{array}$ & & $\begin{array}{c}0.0008^{* * *} \\
(0.0002)\end{array}$ & $\begin{array}{c}0.0007 * * * \\
(0.0002)\end{array}$ & \\
\hline Body Image Index & & $\begin{array}{c}0.0006^{* * *} \\
(0.0001)\end{array}$ & $\begin{array}{c}0.0015^{* * *} \\
(0.0002)\end{array}$ & & $\begin{array}{c}0.0003^{* * *} \\
(0.0001)\end{array}$ & $\begin{array}{c}0.0005^{* * *} \\
(0.0001)\end{array}$ \\
\hline $\begin{array}{l}\text { Chamberlain/Wooldridge } \\
\text { Fixed Effects }\end{array}$ & No & No & No & Yes & Yes & Yes \\
\hline Sample Size & 6308 & 6291 & 9549 & 6308 & 6291 & 9549 \\
\hline
\end{tabular}

See notes to Table 6 . 
Table 10: Linear Regression Estimates of the Persistence of ED-BN Index

\begin{tabular}{|c|c|c|c|c|c|c|c|c|}
\hline \multirow[t]{2}{*}{ Variables } & \multirow[b]{2}{*}{ (1) } & \multirow[b]{2}{*}{$(2)$} & \multirow[b]{2}{*}{ (3) } & \multirow[b]{2}{*}{ (4) } & \multicolumn{3}{|c|}{ Two Stage Least Squares } & \multirow{2}{*}{$\begin{array}{c}\text { Arellano-Bond } \\
(8) \\
\end{array}$} \\
\hline & & & & & $(5)$ & (6) & $(7)$ & \\
\hline Lagged ED-BN Index & $\begin{array}{c}0.444 * * * \\
(0.028)\end{array}$ & $\begin{array}{c}0.436 * * * \\
(0.030)\end{array}$ & $\begin{array}{c}0.355^{* * *} \\
(0.027)\end{array}$ & $\begin{array}{c}0.349 * * * \\
(0.027)\end{array}$ & $\begin{array}{c}0.172^{* * *} \\
(0.063)\end{array}$ & $\begin{array}{c}0.180 * * * \\
(0.058)\end{array}$ & $\begin{array}{c}0.178^{* * *} \\
(0.064)\end{array}$ & $\begin{array}{c}0.232 * * * \\
(0.017)\end{array}$ \\
\hline White & & $\begin{array}{l}-0.005 \\
(0.084)\end{array}$ & $\begin{array}{l}-0.038 \\
(0.085)\end{array}$ & $\begin{array}{l}-0.081 \\
(0.084)\end{array}$ & $\begin{array}{l}-0.105 \\
(0.123)\end{array}$ & $\begin{array}{l}-0.169 \\
(0.121)\end{array}$ & $\begin{array}{c}-0.249 * * * \\
(0.076)\end{array}$ & \\
\hline Parents Some College & & $\begin{array}{c}0.048 \\
(0.107)\end{array}$ & $\begin{array}{c}0.073 \\
(0.101)\end{array}$ & $\begin{array}{c}0.073 \\
(0.101)\end{array}$ & $\begin{array}{c}0.036 \\
(0.154)\end{array}$ & $\begin{array}{c}0.000 \\
(0.153)\end{array}$ & $\begin{array}{l}-0.098 \\
(0.096)\end{array}$ & \\
\hline $\begin{array}{l}\text { Parents Bachelor Degree } \\
\text { or More }\end{array}$ & & $\begin{array}{c}0.107 \\
(0.114)\end{array}$ & $\begin{array}{c}0.122 \\
(0.110)\end{array}$ & $\begin{array}{c}0.131 \\
(0.110)\end{array}$ & $\begin{array}{c}0.005 \\
(0.168)\end{array}$ & $\begin{array}{l}-0.006 \\
(0.167)\end{array}$ & $\begin{array}{l}-0.027 \\
(0.100)\end{array}$ & \\
\hline Income more than $\$ 40,000$ & & $\begin{array}{c}-0.277 * * \\
(0.109)\end{array}$ & $\begin{array}{c}-0.207 * * \\
(0.104)\end{array}$ & $\begin{array}{c}-0.221 * * \\
(0.103)\end{array}$ & $\begin{array}{c}-0.479 * * * \\
(0.160)\end{array}$ & $\begin{array}{c}-0.489 * * * \\
(0.159)\end{array}$ & $\begin{array}{c}-0.383^{* * *} \\
(0.094)\end{array}$ & \\
\hline Distrust Index & & & $\begin{array}{l}-0.019 \\
(0.014)\end{array}$ & $\begin{array}{l}-0.018 \\
(0.014)\end{array}$ & $\begin{array}{c}-0.038^{*} \\
(0.020)\end{array}$ & $\begin{array}{c}-0.042 * * \\
(0.020)\end{array}$ & & \\
\hline Ineffectiveness Index & & & $\begin{array}{c}0.205^{* * *} \\
(0.020)\end{array}$ & $\begin{array}{c}0.188^{* * *} \\
(0.020)\end{array}$ & $\begin{array}{c}0.256^{* * *} \\
(0.029)\end{array}$ & $\begin{array}{c}0.231 * * * \\
(0.028)\end{array}$ & & \\
\hline Perfectionism Index & & & $\begin{array}{c}0.097 * * * \\
(0.013)\end{array}$ & $\begin{array}{c}0.095^{* * *} \\
(0.013)\end{array}$ & $\begin{array}{c}0.132^{* * *} \\
(0.020)\end{array}$ & $\begin{array}{c}0.126 * * * \\
(0.020)\end{array}$ & & \\
\hline First Difference & No & No & No & No & No & No & No & Yes \\
\hline Sample Size & 4151 & 3938 & 3938 & 3928 & 2293 & 2280 & 6841 & 4623 \\
\hline
\end{tabular}

Notes: Standard errors robust to heteroskedasticity and intra-group correlation are reported in parenthesis. NA denotes not applicable; $*$ indicates significant at $10 \%$; ** significant at $5 \%$; *** significant at $1 \%$. Instruments are one-period lags of: all personality indices in column (6); all indices excluding body image in column (5) and only body image in column (7). Regarding the weak IV test, the test statistic should be greater than 32. Regarding the overidentifying test, under the null hypothesis that the overidentifying restrictions are satisified the test statistic should be distributed Chi-Squared(2) and Chi-Square(3) in columns (5) and (6), respectively. The models in columns (7) and (8) are exactly identified. 
Table 11: Tobit Partial Effects Estimates for the Persistence of the ED-BN Index

\begin{tabular}{|c|c|c|c|c|c|c|c|}
\hline & (1) & (2) & (3) & (4) & (5) & (6) & $(7)$ \\
\hline Lagged ED-BN Index & $\begin{array}{l}0.270 * * * \\
(0.013)\end{array}$ & $\begin{array}{c}0.260 * * * \\
(0.014)\end{array}$ & $\begin{array}{l}0.200 * * * \\
(0.012)\end{array}$ & $\begin{array}{c}0.191 * * * \\
(0.011)\end{array}$ & $\begin{array}{c}0.190^{* * *} \\
(0.013)\end{array}$ & $\begin{array}{c}0.180 * * * \\
(0.013)\end{array}$ & $\begin{array}{c}0.177 * * * \\
(0.008)\end{array}$ \\
\hline White & & $\begin{array}{l}-0.038 \\
(0.075)\end{array}$ & $\begin{array}{l}-0.077 \\
(0.070)\end{array}$ & $\begin{array}{c}-0.135^{* *} \\
(0.069)\end{array}$ & & & \\
\hline Age & & $\begin{array}{c}-0.060 * * * \\
(0.014)\end{array}$ & $\begin{array}{c}-0.041 * * * \\
(0.013)\end{array}$ & $\begin{array}{c}-0.058 * * * \\
(0.013)\end{array}$ & & & \\
\hline Parents Some College & & $\begin{array}{c}0.087 \\
(0.090)\end{array}$ & $\begin{array}{c}0.096 \\
(0.083)\end{array}$ & $\begin{array}{c}0.092 \\
(0.081)\end{array}$ & & & \\
\hline $\begin{array}{l}\text { Parents Bachelor Degree } \\
\text { or More }\end{array}$ & & $\begin{array}{c}0.124 \\
(0.103)\end{array}$ & $\begin{array}{c}0.127 \\
(0.095)\end{array}$ & $\begin{array}{c}0.130 \\
(0.095)\end{array}$ & & & \\
\hline Income in $[\$ 20000, \$ 40000]$ & & $\begin{array}{c}-0.248^{* * *} \\
(0.082)\end{array}$ & $\begin{array}{c}-0.224 * * * \\
(0.076)\end{array}$ & $\begin{array}{c}-0.230 * * \\
(0.075)\end{array}$ & & & \\
\hline Income more than $\$ 40,000$ & & $\begin{array}{c}-0.238 * * * \\
(0.091)\end{array}$ & $\begin{array}{c}-0.169 * * \\
(0.086)\end{array}$ & $\begin{array}{c}-0.193^{* *} \\
(0.084)\end{array}$ & & & \\
\hline Distrust Index & & & $\begin{array}{l}-0.007 \\
(0.010)\end{array}$ & $\begin{array}{l}-0.006 \\
(0.009)\end{array}$ & $\begin{array}{l}-0.015 \\
(0.012)\end{array}$ & $\begin{array}{l}-0.015 \\
(0.012)\end{array}$ & \\
\hline Ineffectiveness Index & & & $\begin{array}{c}0.123^{* * *} \\
(0.010)\end{array}$ & $\begin{array}{c}0.098^{* * *} \\
(0.009)\end{array}$ & $\begin{array}{c}0.114^{* * *} \\
(0.011)\end{array}$ & $\begin{array}{c}0.099 * * * \\
(0.011)\end{array}$ & \\
\hline Perfectionism Index & & & $\begin{array}{c}0.066^{* * *} \\
(0.009)\end{array}$ & $\begin{array}{c}0.064 * * * \\
(0.009)\end{array}$ & $\begin{array}{c}0.092^{* * *} \\
(0.013)\end{array}$ & $\begin{array}{c}0.044 * * * \\
(0.018)\end{array}$ & \\
\hline Body Image Index & & & & $\begin{array}{c}0.033 * * * \\
(0.004)\end{array}$ & & $\begin{array}{c}0.033^{* * *} \\
(0.007)\end{array}$ & $\begin{array}{c}0.055^{* * *} \\
(0.005)\end{array}$ \\
\hline $\begin{array}{l}\text { Chamberlain/Wooldridge } \\
\text { Fixed Effects }\end{array}$ & No & No & No & No & Yes & Yes & Yes \\
\hline Sample Size & 4151 & 3938 & 3938 & 3928 & 3938 & 3928 & 6870 \\
\hline
\end{tabular}

See notes to Table 6. 
Table 12: Ordered Probit Coefficient Estimates of the Persistence of ED-BN Index

\begin{tabular}{|c|c|c|c|c|c|c|c|}
\hline Variables & $(1)$ & (2) & (3) & (4) & $(5)$ & $(6)$ & (7) \\
\hline Lagged ED-BN Index [1,5] & $\begin{array}{c}0.838^{* * *} \\
(0.045)\end{array}$ & $\begin{array}{c}0.848^{* * *} \\
(0.047)\end{array}$ & $\begin{array}{c}0.781 * * * \\
(0.048)\end{array}$ & $\begin{array}{c}0.755^{* * *} \\
(0.048)\end{array}$ & $\begin{array}{c}0.716^{* * *} \\
(0.062)\end{array}$ & $\begin{array}{c}0.697 * * * \\
(0.062)\end{array}$ & $\begin{array}{c}0.454 * * * \\
(0.049)\end{array}$ \\
\hline Lagged ED-BN Index $[6,10]$ & $\begin{array}{c}1.436 * * * \\
(0.084)\end{array}$ & $\begin{array}{l}1.415^{* * * *} \\
(0.088)\end{array}$ & $\begin{array}{l}1.202^{* * * *} \\
(0.091)\end{array}$ & $\begin{array}{l}1.174 * * * \\
(0.092)\end{array}$ & $\begin{array}{l}1.068 * * * \\
(0.114)\end{array}$ & $\begin{array}{c}1.036 * * * \\
(0.114)\end{array}$ & $\begin{array}{c}0.797 * * * \\
(0.084)\end{array}$ \\
\hline Lagged ED-BN Index $>10$ & $\begin{array}{c}1.920 * * * \\
(0.118)\end{array}$ & $\begin{array}{c}1.855^{* * *} \\
(0.121)\end{array}$ & $\begin{array}{c}1.590 * * * \\
(0.116)\end{array}$ & $\begin{array}{c}1.554 * * * \\
(0.116)\end{array}$ & $\begin{array}{c}1.458^{* * *} \\
(0.163)\end{array}$ & $\begin{array}{c}1.414^{* * *} \\
(0.164)\end{array}$ & $\begin{array}{c}1.012^{* * *} \\
(0.120)\end{array}$ \\
\hline White & & $\begin{array}{l}-0.016 \\
(0.048)\end{array}$ & $\begin{array}{l}-0.034 \\
(0.051)\end{array}$ & $\begin{array}{l}-0.077 \\
(0.051)\end{array}$ & & & \\
\hline Age & & $\begin{array}{c}-0.042^{* * *} \\
(0.009)\end{array}$ & $\begin{array}{c}-0.033^{* * *} \\
(0.010)\end{array}$ & $\begin{array}{c}-0.046 * * * \\
(0.010)\end{array}$ & & & \\
\hline Parents Some College & & $\begin{array}{c}0.037 \\
(0.058)\end{array}$ & $\begin{array}{c}0.052 \\
(0.059)\end{array}$ & $\begin{array}{c}0.052 \\
(0.060)\end{array}$ & & & \\
\hline $\begin{array}{l}\text { Parents Bachelor Degree } \\
\text { or More }\end{array}$ & & $\begin{array}{l}0.090 \\
(0.065)\end{array}$ & $\begin{array}{l}0.103 \\
(0.067)\end{array}$ & $\begin{array}{c}0.107 \\
(0.068)\end{array}$ & & & \\
\hline Income in $[\$ 20000, \$ 40000]$ & & $\begin{array}{c}-0.167 * * * \\
(0.058)\end{array}$ & $\begin{array}{c}-0.164 * * * \\
(0.060)\end{array}$ & $\begin{array}{c}-0.173^{* * *} \\
(0.060)\end{array}$ & & & \\
\hline Income more than $\$ 40,000$ & & $\begin{array}{c}-0.163^{* * *} \\
(0.061)\end{array}$ & $\begin{array}{c}-0.129 * * \\
(0.063)\end{array}$ & $\begin{array}{c}-0.148^{* *} \\
(0.064)\end{array}$ & & & \\
\hline Distrust & & & $\begin{array}{l}-0.003 \\
(0.007)\end{array}$ & $\begin{array}{l}-0.003 \\
(0.007)\end{array}$ & $\begin{array}{l}-0.005 \\
(0.010)\end{array}$ & $\begin{array}{l}-0.006 \\
(0.010)\end{array}$ & \\
\hline Ineffectiveness Index & & & $\begin{array}{c}0.084^{* * *} \\
(0.006)\end{array}$ & $\begin{array}{c}0.069^{* * *} \\
(0.007)\end{array}$ & $\begin{array}{c}0.083^{* * *} \\
(0.009)\end{array}$ & $\begin{array}{c}0.072^{* * *} \\
(0.010)\end{array}$ & \\
\hline Perfectionism Index & & & $\begin{array}{c}0.050 * * * \\
(0.007)\end{array}$ & $\begin{array}{c}0.049 * * * \\
(0.007)\end{array}$ & $\begin{array}{c}0.074 * * * \\
(0.074)\end{array}$ & $\begin{array}{c}0.072^{* * *} \\
(0.010)\end{array}$ & \\
\hline Body Image Index & & & & $\begin{array}{c}0.023^{* * *} \\
(0.003)\end{array}$ & & $\begin{array}{c}0.029 * * * \\
(0.006)\end{array}$ & $\begin{array}{c}0.045^{* * *} \\
(0.004)\end{array}$ \\
\hline Constant & & & & & $\begin{array}{c}0.597 * * * \\
(0.198)\end{array}$ & $\begin{array}{l}0.484 * * \\
(0.203)\end{array}$ & $\begin{array}{l}-0.074 \\
(0.153)\end{array}$ \\
\hline $\begin{array}{l}\text { Chamberlain/Wooldridge } \\
\text { Fixed Effects }\end{array}$ & No & No & No & No & Yes & Yes & Yes \\
\hline Sample Size & 4151 & 3938 & 3938 & 3928 & 3938 & 3928 & 6870 \\
\hline
\end{tabular}

See notes to Table 6. 
Table 13: Linear Probability Model Estimates of the Persistence of Clinical Bulimia

\begin{tabular}{|c|c|c|c|c|c|c|c|c|}
\hline \multirow[t]{2}{*}{ Variables } & \multirow[b]{2}{*}{ (1) } & \multirow[b]{2}{*}{ (2) } & \multirow[b]{2}{*}{ (3) } & \multirow[b]{2}{*}{ (4) } & \multicolumn{3}{|c|}{ Two Stage Least Squares } & \multirow{2}{*}{$\begin{array}{c}\text { Arellano-Bond } \\
(8) \\
\end{array}$} \\
\hline & & & & & $(5)$ & $(6)$ & $(7)$ & \\
\hline Lagged Clinical Bulimia & $\begin{array}{c}0.196^{* * *} \\
(0.043)\end{array}$ & $\begin{array}{c}0.181 * * * \\
(0.043)\end{array}$ & $\begin{array}{c}0.150^{* * *} \\
(0.041)\end{array}$ & $\begin{array}{c}0.149 * * * \\
(0.041)\end{array}$ & $\begin{array}{c}0.021 \\
(0.134)\end{array}$ & $\begin{array}{c}0.014 \\
(0.128)\end{array}$ & $\begin{array}{c}0.086 \\
(0.129)\end{array}$ & $\begin{array}{c}0.075 * * \\
(0.037)\end{array}$ \\
\hline White & & $\begin{array}{l}-0.003 \\
(0.005)\end{array}$ & $\begin{array}{l}-0.005 \\
(0.005)\end{array}$ & $\begin{array}{l}-0.005 \\
(0.005)\end{array}$ & $\begin{array}{l}-0.007 \\
(0.008)\end{array}$ & $\begin{array}{l}-0.008 \\
(0.008)\end{array}$ & $\begin{array}{l}-0.006 \\
(0.004)\end{array}$ & \\
\hline Age & & $\begin{array}{c}-0.004 * * * \\
(0.001)\end{array}$ & $\begin{array}{c}-0.002^{* *} \\
(0.001)\end{array}$ & $\begin{array}{c}-0.003^{* *} \\
(0.001)\end{array}$ & $\begin{array}{l}-0.002 \\
(0.001)\end{array}$ & $\begin{array}{l}-0.002 \\
(0.001)\end{array}$ & $\begin{array}{c}-0.004 * * * \\
(0.001)\end{array}$ & \\
\hline Parents Some College & & $\begin{array}{l}-0.000 \\
(0.006)\end{array}$ & $\begin{array}{c}0.001 \\
(0.006)\end{array}$ & $\begin{array}{c}0.001 \\
(0.006)\end{array}$ & $\begin{array}{l}-0.004 \\
(0.010)\end{array}$ & $\begin{array}{l}-0.004 \\
(0.010)\end{array}$ & $\begin{array}{l}-0.006 \\
(0.005)\end{array}$ & \\
\hline $\begin{array}{l}\text { Parents Bachelor Degree } \\
\text { or More }\end{array}$ & & $\begin{array}{c}0.004 \\
(0.007)\end{array}$ & $\begin{array}{c}0.006 \\
(0.007)\end{array}$ & $\begin{array}{c}0.006 \\
(0.007)\end{array}$ & $\begin{array}{c}0.003 \\
(0.011)\end{array}$ & $\begin{array}{c}0.003 \\
(0.011)\end{array}$ & $\begin{array}{l}-0.001 \\
(0.005)\end{array}$ & \\
\hline Income in $[\$ 20000, \$ 40000]$ & & $\begin{array}{l}-0.009 \\
(0.007)\end{array}$ & $\begin{array}{l}-0.007 \\
(0.007)\end{array}$ & $\begin{array}{l}-0.007 \\
(0.007)\end{array}$ & $\begin{array}{l}-0.010 \\
(0.010)\end{array}$ & $\begin{array}{l}-0.010 \\
(0.010)\end{array}$ & $\begin{array}{c}-0.009 * \\
(0.005)\end{array}$ & \\
\hline Income more than $\$ 40,000$ & & $\begin{array}{c}-0.012^{* *} \\
(0.006)\end{array}$ & $\begin{array}{l}-0.009 \\
(0.006)\end{array}$ & $\begin{array}{l}-0.009 \\
(0.006)\end{array}$ & $\begin{array}{l}-0.010 \\
(0.010)\end{array}$ & $\begin{array}{l}-0.011 \\
(0.010)\end{array}$ & $\begin{array}{c}-0.014^{* * *} \\
(0.005)\end{array}$ & \\
\hline Distrust Index & & & $\begin{array}{l}-0.001 \\
(0.001)\end{array}$ & $\begin{array}{l}-0.001 \\
(0.001)\end{array}$ & $\begin{array}{l}-0.002 \\
(0.001)\end{array}$ & $\begin{array}{c}-0.002 * \\
(0.001)\end{array}$ & & \\
\hline Ineffectiveness Index & & & $\begin{array}{c}0.008^{* * *} \\
(0.001)\end{array}$ & $\begin{array}{c}0.008^{* * *} \\
(0.002)\end{array}$ & $\begin{array}{c}0.010^{* * *} \\
(0.002)\end{array}$ & $\begin{array}{c}0.010^{* * *} \\
(0.002)\end{array}$ & & \\
\hline Perfectionism Index & & & $\begin{array}{c}0.003^{* * *} \\
(0.001)\end{array}$ & $\begin{array}{c}0.003^{* * *} \\
(0.001)\end{array}$ & $\begin{array}{c}0.005^{* * *} \\
(0.002)\end{array}$ & $\begin{array}{c}0.005^{* * *} \\
(0.001)\end{array}$ & & \\
\hline Body Image Index & & & & $\begin{array}{c}0.001 \\
(0.000)\end{array}$ & & $\begin{array}{c}0.001 * * \\
(0.001)\end{array}$ & $\begin{array}{c}0.002^{* * *} \\
(0.000)\end{array}$ & $\begin{array}{c}0.001^{* * *} \\
(0.000)\end{array}$ \\
\hline Constant & $\begin{array}{c}0.016^{* * *} \\
(0.002)\end{array}$ & $\begin{array}{c}0.084 * * * \\
(0.019)\end{array}$ & $\begin{array}{c}0.023 \\
(0.020)\end{array}$ & $\begin{array}{c}0.024 \\
(0.020)\end{array}$ & $\begin{array}{c}0.010 \\
(0.024)\end{array}$ & $\begin{array}{c}0.011 \\
(0.024)\end{array}$ & $\begin{array}{c}0.077 * * * \\
(0.025)\end{array}$ & $\begin{array}{c}0.029 * * * \\
(0.008)\end{array}$ \\
\hline Weak IV test & NA & NA & NA & NA & $38.237 * * *$ & $39.927 * * *$ & $36.946^{* * *}$ & $293.12^{* * *}$ \\
\hline Overidentification Test & NA & NA & NA & NA & 2.259 & 2.811 & NA & NA \\
\hline First Difference & No & No & No & No & No & No & No & Yes \\
\hline Sample Size & 4151 & 3938 & 3938 & 3928 & 2293 & 2280 & 6841 & 4623 \\
\hline
\end{tabular}

See notes to Table 10. 
Table 14: Probit Partial Effects Estimates for the Persistence of Clinical Bulimia

\begin{tabular}{|c|c|c|c|c|c|c|c|}
\hline & $(1)$ & (2) & (3) & (4) & (5) & (6) & $(7)$ \\
\hline Lagged Clinical Bulimia & $\begin{array}{c}0.196 * * * \\
(0.043)\end{array}$ & $\begin{array}{c}0.148^{* * *} \\
(0.040)\end{array}$ & $\begin{array}{c}0.061 * * * \\
(0.023)\end{array}$ & $\begin{array}{c}0.056^{* * *} \\
(0.022)\end{array}$ & $\begin{array}{c}0.0074 \\
(0.0103)\end{array}$ & $\begin{array}{c}0.007 \\
(0.010)\end{array}$ & $\begin{array}{c}0.008 \\
(0.008)\end{array}$ \\
\hline White & & $\begin{array}{l}-0.002 \\
(0.004)\end{array}$ & $\begin{array}{l}-0.005 \\
(0.003)\end{array}$ & $\begin{array}{c}-0.006^{* *} \\
(0.003)\end{array}$ & & & \\
\hline Age & & $\begin{array}{c}-0.003^{* * *} \\
(0.001)\end{array}$ & $\begin{array}{c}-0.002 * * \\
(0.001)\end{array}$ & $\begin{array}{c}-0.002 * * * \\
(0.000)\end{array}$ & & & \\
\hline Parents Some College & & $\begin{array}{l}-0.000 \\
(0.005)\end{array}$ & $\begin{array}{c}0.000 \\
(0.003)\end{array}$ & $\begin{array}{c}0.000 \\
(0.003)\end{array}$ & & & \\
\hline $\begin{array}{l}\text { Parents Bachelor Degree } \\
\text { or More }\end{array}$ & & $\begin{array}{c}0.003 \\
(0.006)\end{array}$ & $\begin{array}{c}0.003 \\
(0.004)\end{array}$ & $\begin{array}{c}0.003 \\
(0.004)\end{array}$ & & & \\
\hline Income in $[\$ 20000, \$ 40000]$ & & $\begin{array}{l}-0.006 \\
(0.004)\end{array}$ & $\begin{array}{l}-0.004 \\
(0.003)\end{array}$ & $\begin{array}{l}-0.004 \\
(0.003)\end{array}$ & & & \\
\hline Income more than $\$ 40,000$ & & $\begin{array}{c}-0.009 * * \\
(0.005)\end{array}$ & $\begin{array}{l}-0.004 \\
(0.003)\end{array}$ & $\begin{array}{l}-0.004 \\
(0.003)\end{array}$ & & & \\
\hline Distrust Index & & & $\begin{array}{l}-0.001 \\
(0.001)\end{array}$ & $\begin{array}{l}-0.001 \\
(0.001)\end{array}$ & $\begin{array}{l}-0.0003 \\
(0.0003)\end{array}$ & $\begin{array}{c}0.001 \\
(0.001)\end{array}$ & \\
\hline Ineffectiveness Index & & & $\begin{array}{c}0.002^{* * *} \\
(0.000)\end{array}$ & $\begin{array}{c}0.002^{* * *} \\
(0.000)\end{array}$ & $\begin{array}{c}0.0006 \\
(0.0005)\end{array}$ & $\begin{array}{c}0.001 \\
(0.001)\end{array}$ & \\
\hline Perfectionism Index & & & $\begin{array}{c}0.001 * * * \\
(0.000)\end{array}$ & $\begin{array}{c}0.001^{* * *} \\
(0.000)\end{array}$ & $\begin{array}{c}0.0004 \\
(0.0004)\end{array}$ & $\begin{array}{c}0.001 \\
(0.001)\end{array}$ & \\
\hline Body Image Index & & & & $\begin{array}{c}0.001 \\
(0.001)\end{array}$ & & $\begin{array}{c}0.001 \\
(0.001)\end{array}$ & $\begin{array}{c}0.001 \\
(0.001)\end{array}$ \\
\hline $\begin{array}{l}\text { Chamberlain/Wooldridge } \\
\text { Fixed Effects }\end{array}$ & No & No & No & No & Yes & Yes & Yes \\
\hline Sample Size & 4151 & 3938 & 3938 & 3928 & 3938 & 3928 & 6870 \\
\hline
\end{tabular}


Table 15: Linear Regression Estimates for Rational Addiction Model of ED-BN Index

\begin{tabular}{|c|c|c|c|c|c|}
\hline \multirow[t]{2}{*}{ Variables } & \multirow[b]{2}{*}{$(1)$} & \multirow[b]{2}{*}{$(2)$} & \multirow[b]{2}{*}{ (3) } & \multicolumn{2}{|c|}{2 Stage Least Squares } \\
\hline & & & & (4) & $(5)$ \\
\hline Lag of ED-BN Index & $\begin{array}{c}0.292 * * * \\
(0.015)\end{array}$ & $\begin{array}{c}0.261 * * * \\
(0.023)\end{array}$ & $\begin{array}{c}0.272^{* * *} \\
(0.016)\end{array}$ & $\begin{array}{c}0.148 * * \\
(0.061)\end{array}$ & $\begin{array}{c}0.176^{* * *} \\
(0.056)\end{array}$ \\
\hline Lead of ED-BN Index & $\begin{array}{c}0.409 * * * \\
(0.025)\end{array}$ & $\begin{array}{c}0.335^{* * * *} \\
(0.031)\end{array}$ & $\begin{array}{c}0.394^{* * *} \\
(0.026)\end{array}$ & $\begin{array}{l}0.169 * \\
(0.097)\end{array}$ & $\begin{array}{c}0.188 * * \\
(0.089)\end{array}$ \\
\hline White & & $\begin{array}{l}-0.049 \\
(0.083)\end{array}$ & $\begin{array}{c}-0.137 * * * \\
(0.048)\end{array}$ & $\begin{array}{l}-0.124 \\
(0.095)\end{array}$ & $\begin{array}{c}-0.247 * * * \\
(0.078)\end{array}$ \\
\hline Age & & $\begin{array}{c}-0.101 * * * \\
(0.018)\end{array}$ & $\begin{array}{c}-0.122 * * * \\
(0.017)\end{array}$ & $\begin{array}{c}-0.118^{* * *} \\
(0.019)\end{array}$ & $\begin{array}{c}-0.149 * * * \\
(0.020)\end{array}$ \\
\hline Parents Some College & & $\begin{array}{c}0.022 \\
(0.102)\end{array}$ & $\begin{array}{l}-0.087 \\
(0.065)\end{array}$ & $\begin{array}{l}-0.053 \\
(0.109)\end{array}$ & $\begin{array}{c}-0.166^{*} \\
(0.088)\end{array}$ \\
\hline Parents Bachelor Degree or More & & $\begin{array}{c}0.020 \\
(0.109)\end{array}$ & $\begin{array}{l}-0.038 \\
(0.068)\end{array}$ & $\begin{array}{l}-0.066 \\
(0.126)\end{array}$ & $\begin{array}{l}-0.112 \\
(0.101)\end{array}$ \\
\hline Income in $[\$ 20000, \$ 40000]$ & & $\begin{array}{c}-0.208^{* *} \\
(0.102)\end{array}$ & $\begin{array}{c}-0.187 * * * \\
(0.064)\end{array}$ & $\begin{array}{c}-0.262^{* *} \\
(0.111)\end{array}$ & $\begin{array}{c}-0.262^{* * *} \\
(0.092)\end{array}$ \\
\hline Income more than $\$ 40,000$ & & $\begin{array}{c}-0.194 * \\
(0.104)\end{array}$ & $\begin{array}{c}-0.255^{* * *} \\
(0.063)\end{array}$ & $\begin{array}{c}-0.250 * * \\
(0.120)\end{array}$ & $\begin{array}{c}-0.348^{* * *} \\
(0.100)\end{array}$ \\
\hline Distrust Index & & $\begin{array}{l}-0.021 \\
(0.015)\end{array}$ & & $\begin{array}{l}-0.012 \\
(0.013)\end{array}$ & \\
\hline Ineffectiveness Index & & $\begin{array}{c}0.144^{* * *} \\
(0.019)\end{array}$ & & $\begin{array}{c}0.183^{* * *} \\
(0.017)\end{array}$ & \\
\hline Perfectionism Index & & $\begin{array}{c}0.097 * * * \\
(0.014)\end{array}$ & & $\begin{array}{c}0.115^{* * *} \\
(0.013)\end{array}$ & \\
\hline Body Image Index & & $\begin{array}{c}0.018^{* * *} \\
(0.005)\end{array}$ & $\begin{array}{c}0.040^{* * *} \\
(0.004)\end{array}$ & $\begin{array}{c}0.026^{* * *} \\
(0.006)\end{array}$ & $\begin{array}{c}0.059 * * * \\
(0.007)\end{array}$ \\
\hline Constant & $\begin{array}{c}0.360 * * * \\
(0.029)\end{array}$ & $\begin{array}{c}1.213^{* * * *} \\
(0.309)\end{array}$ & $\begin{array}{c}2.288^{* * *} \\
(0.285)\end{array}$ & $\begin{array}{c}1.641^{* * *} \\
(0.346)\end{array}$ & $\begin{array}{c}3.066^{* * *} \\
(0.383)\end{array}$ \\
\hline Sample Size & 5198 & 3280 & 4897 & 3249 & 4855 \\
\hline
\end{tabular}

Notes: Standard errors are in parenthesis. In columns (1)-(5) standard errors are robust to heteroskedasticity and intra-individual correlation.* indicates significant at 10\%; ** at 5\%; *** $1 \%$. Instruments for 2 SLS estimates are lag and lead of Body Image Index. We do not conduct a test for weak instruments as rules of thumb have not be developed when there are multiple endogenous variables. 


\section{Appendix}

\section{A Data Variable Definitions}

The correspondence with the NHLBI project office helped us to identify the items that make up the indices used in our analysis. We describe the construction of the ED-BN index, body image, and perfectionism indices in the main text of the paper. The distrust index is based on the subjects responses to seven items: 1) I tell people about my feelings; 2) I trust people; 3) I can talk to other people easily; 4). I have close friends; 5) I have trouble telling other people how I feel; 6) I don't want people to get to know me very well; and 7) I can talk about my private thoughts or feelings. The scoring rule is as follows: "always" $=1$, "usually" $=2$, "often" $=3$, "sometimes" $=4$, "rarely" $=5$, and "never" $=6$ in questions 5 and 6 ; and "always" $=6$, "usually" $=5$, "often" $=4$, "sometimes" $=3$, "rarely" $=2$, and "never" $=1$ in questions $1,2,3,4$, and 7 . A response of 4-6 on a given question contributes zero points to the distrust index; a response of 3 contributes 1 point; a response of 2 contributes 2 points; and a response of 1 contributes 3 points. The distrust index is a sum of all contributing points.

The ineffectiveness index is based on the subjects responses to ten items: 1) I feel I can't do things very well; 2) I feel very alone; 3) I feel I can't handle things in my life; 4) I wish I were someone else; 5) I don't think I am as good as other kids; 6) I feel good about myself; 7) I don't like myself very much; 8) I feel I can do whatever I try to do; 9) I feel I am a good person; 10) I feel empty inside. The scoring rule is as follows: "always" $=1$, "usually" $=2$, "often" $=3$, "sometimes" $=4$, "rarely" $=5$, and "never" $=6$ in questions $1,2,3,4,5,7$, and 10; and "always" $=6$, "usually" $=5$, "often" $=4$, "sometimes" $=3$, "rarely" $=2$, and "never" $=1$ in questions 6,8 , and 9. A response of 4-6 on a given question contributes zero points to the ineffectiveness index; a response of 3 contributes 1 point; a response of 2 contributes 2 points; and a response of 1 contributes 3 points. The ineffectiveness index is a sum of all contributing points.

Table A.1: Variable Definitions

\begin{tabular}{|c|c|c|c|}
\hline Variable & Description & Coding & Waves \\
\hline ED-BN Index & Eating Disorders Bulimia Subscale & Categorical Variable; Range 0-21 & $3,5,7,9,10$ \\
\hline Clinical Bulimia & Case of Clinical Bulimia & $=1$ if ED-BN Index $>10 ;=0$ Otherwise & $3,5,7,9,10$ \\
\hline Body Image Index & Measures Poor Body Image Concerns & Categorical Variable; Range 0-27 & $3,5,7,9,10$ \\
\hline Perfectionism Index & Measures Driveness for Perfection & Categorical Variable; Range $0-18$ & $3,5,9,10$ \\
\hline Ineffectiveness Index & Measures Feelings of Ineffectiveness & Categorical Variable; Range 0-29 & $3,5,9,10$ \\
\hline Distrust Index & Measures Interpersonal Distrust & Categorical Variable; Range $0-21$ & $3,5,9,10$ \\
\hline Age & Respondent Age & & All 10 \\
\hline White & Respondent Race is White & $=1$ if Race is White; $=0$ if African American & 1 \\
\hline Parents High School or Less & Highest Education of Parents & Dummy Variable Highest Education High School or Less & 1 \\
\hline Parents Some College & Highest Education of Parents & Dummy Variable Highest Education Some College & 1 \\
\hline Parents Bachelor Degree or More & Highest Education of Parents & Dummy Variable Highest Education College Degree or More & 1 \\
\hline Income less than $\$ 20,000$ & Household income (in 1988\$) & Dummy Variable Household Income is Less than $\$ 20,000$ & 1 \\
\hline Income in $[\$ 20000, \$ 40000]$ & Household income (in 1988\$) & Dummy Variable Household Income is in Range $[\$ 20,000, \$ 40,000]$ & 1 \\
\hline Income more than $\$ 40,000$ & Household income (in 1988\$) & Dummy Variable Household Income is Higher than $\$ 40,000$ & 1 \\
\hline
\end{tabular}

